\title{
The Cauchy 5 Small, Low-Volume Lunar Shield Volcano: Evidence for Volatile Exsolution-Eruption Patterns and Type 1/Type 2 Hybrid Irregular Mare Patch (IMP) Formation \\ Le Qiao ${ }^{1,2}$, James W. Head ${ }^{2}$, Lionel Wilson ${ }^{3}$, Zongcheng Ling ${ }^{1}$
}

${ }^{1}$ Shandong Key Laboratory of Optical Astronomy and Solar-Terrestrial Environment, School of Space Science and Physics, Institute of Space Sciences, Shandong University, Weihai, Shandong, 264209, China.

${ }^{2}$ Department of Earth, Environmental and Planetary Sciences, Brown University, Providence, RI 02912, USA.

${ }^{3}$ Lancaster Environment Centre, Lancaster University, Lancaster LA1 4YQ, UK.

Corresponding authors: Le Qiao (leqiao.geo@gmail.com), Zongcheng Ling (zcling@sdu.edu.cn)

Key Points:

- Cauchy 5 small shield volcano displays two types of IMPs: Type 1 (mound + floor) in its summit pit and Type 2 (pit only) on its flanks

- Small edifice volume maximizes volatile exsolution and favors strombolian lava lake activity and emplacement of vesicular flank lavas

- Relationships at Cauchy 5 summit and flanks provide a link to understanding the genetic relationship between the two IMP sub-types 


\begin{abstract}
The lunar shield volcano Cauchy 5, sitting at the low diameter-height-volume end of the population, is the only known example containing two different types of Irregular Mare Patches (IMPs) in very close association: 1) the pit crater interior Type 1 IMP composed of bleb-like mounds surrounded by a hummocky and blocky floor unit, and 2) Type 2 IMPs, small, often optically immature pits $<\sim 5$ meters deep, located on the generally block-deficient shield flanks. A four-phase lunar magma ascent/eruption model predicts that during a relatively brief eruption, low magma rise rates maximize volatile exsolution in lava filling the pit crater. Bubble-rich magmas overtop the pit crater and form extremely bubble-rich/vesicular flows on the shield flanks. Exposure of the flanking flows to vacuum produces a fragmental layer of exploded glassy bubble walls. Subsequent second boiling upon cooling of the flanking flow interiors releases additional volatiles which migrate and collect, forming magmatic foams and gas pockets. As magma rise rates slow, trapped gas and magmatic foam build up below the cooling pit crater floor. Magmatic foams are extruded to form Type 1 IMP deposits. Type 2 IMPs on the flanks are interpreted to be due primarily to subsequent impacts causing collapse of the flow surface layer into the extremely vesicle- and void-rich flow interior. Anomalously young pit crater floor/shield flank crater retention ages compared with surrounding maria ages may be due to effects of Cauchy 5 substrate characteristics (extreme micro- and macro-porosity, foamy nature and glassy auto-regolith) on superposed crater formation and retention.
\end{abstract}

\title{
Plain Language Summary
}

A group of distinctive and unusual features in the lunar maria known as "Irregular Mare Patches" (IMPs) are of two types: Type 1 ("mound + floor") usually occurring in volcanic pit craters and related depressions, and dated to less than 100 Ma old, and Type 2 ("pit only") occurring as scattered pits in localized areas of the lunar maria and too small to obtain ages. We investigated Cauchy 5, a small lava shield that is anomalous in that both Type 1 and Type 2 IMPs occur in very close association. Models of magma ascent and eruption in small-volume, low-volume-flux mare basalt eruptions show that gas exsolution is optimized. Gas release patterns and pit crater lava lake behavior produce Type 1 IMPs on the lava lake floor and Type 2 IMPs on the shield volcano flanks from void collapse and subsequent impacts. The extremely vesicular, void-rich and foam-like nature of the lava lake floor and shield flank flows forms a substrate whose characteristics are predicted to significantly influence the formation and degradation of superposed impact craters. This potentially causes the IMPs to appear to be much younger than the adjacent mare units.

\section{Introduction and Background:}

\subsection{Lunar Mare Volcanism: Styles of Emplacement and Duration of Process in Lunar History}

Lunar mare basalt volcanism represents a major phase of secondary crust formation (Taylor, 1989) in the evolution of the Moon (Wieczorek et al., 2006). Eruptions vary in their associated surface morphology (pit craters, cones, small shields, long lava flows, pyroclastic blankets) and inferred eruption conditions (intrusive, effusive, explosive) (Figure 1). Models of the generation, ascent and eruption of lunar basaltic magmas (e.g., Wilson \& Head, 1981; Head \& Wilson, 1992, 2017; Wilson \& Head, 2017a,b; Rutherford et al., 2017; Wilson et al., 2019) have provided a predictive basis to relate dike emplacement events to near-surface and surface mare basalt 
morphologic features and structures (Head \& Wilson, 2017). In addition, detailed models of the stages or phases in individual mare basalt eruptions (Wilson \& Head, 2018) can be used to place individual eruptive morphologic features into both dike emplacement scenarios (Figure 1) and the sequence and dominant phases characterizing the eruption.

Critically important to understanding the thermal evolution of the Moon is the time of onset, peak flux and cessation of the eruptive activity associated with lunar mare volcanism. The vast majority of basaltic volcanism occurred between 3.9 and 3.1 Ga ago and cessation is generally thought to have occurred more than a billion years ago (Hiesinger et al., 2011) (see Figure 1 in Head \& Wilson, 2017). Recently, the discovery and documentation of dozens of morphologically fresh, optically immature features associated with the lunar maria, termed Irregular Mare Patches (IMPs) (Braden et al., 2014), has challenged this conventional view. Superposed impact crater size-frequency distribution (CSFD) data for the three largest IMPs yield ages of 18, 33 and 58 Ma (Braden et al., 2014), all within the last two percent of lunar history and raising the question: Could the Moon be volcanically active today?

\subsection{Irregular Mare Patches (IMPs) and Implications for the Duration of Mare Volcanism in Lunar History}

1) Background and initial interpretation: The most prominent of the lunar IMPs, the enigmatic Ina structure $\left(18.65^{\circ} \mathrm{N}, 5.30^{\circ} \mathrm{E}\right)$, is composed of a distinctive series of bleb-like mounds and intervening optically immature (low levels of space weathering spectral effects on soil maturation) hummocky and blocky floor units, and has intrigued lunar scientists for decades following its discovery on Apollo photographs in the 1970s (Whitaker, 1972). Investigations using high-resolution Lunar Reconnaissance Orbiter Narrow Angle Camera (LROC NAC) images identified dozens of lunar IMPs, all with textures and structures resembling Ina (Stooke, 2012; Braden et al., 2014; Zhang et al., 2018). Qiao et al. (2019b) recently gathered IMP identifications from multiple prior studies and presented an updated catalog of more than eighty IMPs. Collectively, these features range from $100 \mathrm{~m}$ to $5 \mathrm{~km}$ in maximum dimension and all occur in association with the lunar maria. To improve our understanding of the entire IMP population, Qiao et al. (2019b) surveyed the detailed geological characteristics and structures of each cataloged IMP feature and derived a preliminary classification scheme for IMP characteristics. In this scheme, all the mapped IMPs can be subdivided into two categories. Type 1 IMPs are a small number $(\mathrm{n}=5)$ of larger features $(2-5 \mathrm{~km}$ in dimension) composed of a combination of positive-relief mounds emplaced on surfaces consisting of rough hummocky terrains ("mound + floor" type or mound-type). Type 1 IMPs are usually related to small shield volcano summit pit craters and vent-like structures (e.g., Ina and Sosigenes). Type 2 IMPs comprise a much larger number $(\mathrm{n}=76)$ of smaller features $(60 \mathrm{~m}$ to $1.2 \mathrm{~km}$ in length, average greatest dimensions less than $300 \mathrm{~m}$ ) and are composed of rough, bright pitted terrains ("pit only" type or pit-type), typically having no clear relation to a small shield summit pit crater or vent (true of at least 67 IMPs among the updated catalog of 81 IMPs by Qiao et al., 2019b).

The five large Type 1 IMPs, Ina, Sosigenes, Cauchy 5, Nubium and Maskelyne (2-5 km in maximum dimension), all have isolated smooth mounded units surrounded by rough floor terrains (e.g., Schultz et al., 2006; Garry et al., 2012; Braden et al., 2014; Stopar et al., 2017; Qiao et al., 2019b) and are of sufficient size to obtain CSFD-based model ages. Braden et al. (2014) found that the smooth mound deposits associated with three of these IMP features gave model ages all younger than $100 \mathrm{Ma}$ (Sosigenes, $18 \pm 1 \mathrm{Ma}$; Ina, $33 \pm 2 \mathrm{Ma}$; Cauchy 5, $58 \pm 4$ 
Ma). Valantinas et al. (2018) recently reported a model age of $48 \pm 5 \mathrm{Ma}$ for the Nubium IMP mound terrains. On the basis of these ages and other observations, including optical freshness and distinctive mound-like shapes with sharp boundaries, Braden et al. (2014) interpreted the unusual morphology of these features to represent small mare volcanic eruptions that occurred "significantly after the established cessation of lunar mare basaltic volcanism". Such geologically very recent eruptions would suggest a prolonged duration of lunar volcanism that appears to be in conflict with the established thermal evolution of the Moon (e.g., Wieczorek et al., 2006). Braden et al. (2014) envisioned a process in which the relatively steep-sided mounds represent small basalt extrusions with the stratigraphically lower "uneven" deposits as fragmented basalt or lava lake crust within the eruptive vent formed during the collapse of the vent.

The vast majority of IMPs are much smaller than the five largest (in maximum dimension) mentioned above and cannot be dated with the CSFD techniques (the remaining population averaged $<300 \mathrm{~m}$ in longest dimension; average length $=275 \mathrm{~m}, \mathrm{n}=76$; Qiao et al., 2019b). These small Type 2 IMPs share some of their morphologic characteristics with the large Type 1 IMPs, while also showing many morphological and geologic context differences. The smaller Type 2 IMPs are characterized by many irregularly shaped, rough textured pits and lack the characteristic bleb-like raised mound structures seen at the five largest Type 1 IMPs. The smaller Type 2 IMPs are also generally not related to volcanic pit craters or vents. The larger Type 1 IMPs, however, are commonly associated with volcanic pit craters and often have isolated smooth raised mounds surrounded by rough floor terrains; these smooth mounded deposits always have lobate margins and steep boundary slopes, and are interpreted (Braden et al., 2014) to be superposed on the surrounding uneven floor deposits. So, it is unknown whether the two IMP sub-types have similar or different origins due to the fact that 1) the morphologies of the sub-types have some similarities, but are also different in many aspects (the Type 2 IMPs typically do not have individual mounds surrounded by rough terrain), 2) the Type 1 and 2 IMPs do not occur in close proximity, and 3) the Type 2 IMPs are generally too small to date confidently and thus cannot be assumed to be of the same young age or origin (Braden et al., 2014).

2) Subsequent and additional interpretations for the origin of IMPs: Following the identification and documentation of over eighty IMPs and the dating of the several large Type 1 IMPs, interpretations different from that of Braden et al. (2014) have also been proposed. These include pyroclastic deposition (Carter et al., 2013), contemporaneous emplacement with the adjacent ancient mare deposits, with deposits of elevated blockiness (Bennett et al., 2015), some style of explosive process (either pyroclastic deposition or removal of surface materials by outgassing) (Schultz et al., 2006; Elder et al., 2017) and some geological process other than Copernican-age lava flow emplacement (Neish et al., 2017). However, these subsequently and previously proposed IMP origin models are either very general (e.g., Bennett et al., 2015; Elder et al., 2017; Neish et al., 2017), or have not been able to reproduce all the observed IMP characteristics (e.g., Schultz et al., 2006; Garry et al., 2012; Braden et al., 2014; see a more detailed assessment in Qiao et al., 2018).

Wilson and Head (2017a) pointed out that lunar volcanic eruptions occur in conditions very different from those on Earth, especially in the consideration of lower lunar gravity and lack of an atmosphere (Head \& Wilson, 2017; Wilson \& Head, 2017b), which results in unusual volcanic deposits neither predicted by models nor observed on Earth in the final phases of 
eruptions. Wilson and Head (2017a) assessed the physical volcanology of the final stages of eruptions in small shield volcano summit vent floors, such as Ina, and showed that many observed characteristics of Type 1 IMPs could be explained by these final-stage eruptive activities. Specifically, as the magma ascent rate approaches zero, volatiles exsolve in the top part of the dike and lava lake to form a highly vesicular foam. As the dike begins to close due to the elastic response of the crust, the foam is squeezed upward and extruded through cracks in the chilled and porous lava lake crust as the crust is deformed. Wilson and Head (2017a) interpreted the hummocky and blocky floor units at lunar Type 1 IMPs as the very porous solidified lava lake crust, and the final-stage magmatic foam extrusions as the mechanism that produces convex mounds; aerogel-like foam physical properties modify typical impact cratering and regolith production on the mounds, potentially retaining a youthful surface (see the mechanisms in more details in Wilson \& Head, 2017a; Qiao et al., 2017, 2018, 2019a).

Qiao et al. (2017, 2019a) analyzed the Ina feature (a Type 1 IMP) and confirmed that the structure was the summit pit crater of a $\sim 22 \mathrm{~km}$ diameter, $\sim 3.5 \mathrm{Ga}$ old shield volcano (Strain \& El-Baz, 1980). The morphology of the mounds and rough floor of Ina were interpreted to be consistent with the lava lake and magmatic foam formation scenario (Wilson \& Head, 2017a). Furthermore, when the effects of impacts into magmatic foam were taken into consideration (crushing of the foam, minimal ejecta and much smaller diameter crater), the CSFD of the mounds was more consistent with that of the ancient $\sim 3.5$ Ga old shield volcano on which Ina pit crater resides. Qiao et al. $(2017,2019$ a) concluded that Ina represented an example of the unusual eruption styles likely in summit pit craters during late-stage extrusion of magma made foamy by the unusual low-gravity, essentially zero-atmospheric pressure lunar environment (Wilson \& Head, 2017b). Qiao et al. (2018) also analyzed the second of the large Type 1 IMP features, the elongate Sosigenes depression, a structure associated with a dike emplacement event in Mare Tranquillitatis, and reached similar conclusions. Thus, the proposed late-stage degassing and magmatic foam formation mechanism (Wilson \& Head, 2017a; Qiao et al., 2017, 2018, 2019a) offers an alternative interpretation to account for the main features of the two major occurrences of Type 1 IMPs, without resorting to lunar volcanic activity occurring in the last 100 million years.

\subsection{The Cauchy 5 Small Shield Volcano: A Hybrid Example of the Two Types of Lunar IMPs}

Small lunar shield volcanoes (Head \& Gifford, 1980) represent the low-volume, loweffusion rate end of the lunar mare basalt eruption spectrum (Head \& Wilson, 2017; their section 3.5.2) (Figure 1). In the current analysis, we chose to investigate the Cauchy 5 small shield volcano in Mare Tranquillitatis because: 1 ) it has both a large Type 1 IMP in its summit pit crater (Braden et al., 2014) and a population of over a hundred small Type 2 IMPs on the shield flanks, 2) it has an elongate summit pit crater whose depth reaches several tens of meters below the shield into the pre-shield substrate, and 3) superposed impact craters yield a CSFD interpreted to represent an age of $\sim 58 \mathrm{Ma}$ (Braden et al., 2014), more than three billion years younger than surrounding mare basalt units (Hiesinger et al., 2011). Analysis of Cauchy 5 offers the opportunity to assess: 1) the origin of IMPs, 2) the ages of IMPs and 3) the relationships between the two sub-types of IMPs in terms of their mode(s) of origin through physical volcanology analyses and geological characterization. 
We first describe the setting and characteristics of the Cauchy 5 small shield volcano and its related deposits and features. Secondly, we explore the predictions of models for the intrusion and eruption of dikes producing small-volume eruptions (Head \& Wilson, 2017) and the nature of the predicted effusion and volatile release phases in such eruptions (Rutherford et al., 2017; Wilson \& Head, 2018). We then compare these predictions with the characteristics of the Cauchy 5 small shield volcano and the two types of IMP, and conclude with a discussion of the formation of Cauchy 5 and the origin of the unusual ages of its IMP populations.

\section{The Cauchy 5 Small Shield Volcano and Associated Type 1 and Type 2 IMPs: Geologic Setting and Characteristics}

The Cauchy 5 small shield volcano, located in Mare Tranquillitatis $\left(7.169^{\circ} \mathrm{N}, 37.592^{\circ} \mathrm{E}\right)$ (Figures 2 and 3), is a circular mound about 5-6 km in base diameter and $\sim 40 \mathrm{~m}$ high at its summit (Figure 4). The flanks of the small shield slope away from the summit pit crater to the base of the shield (2-6 $6^{\circ}$ slopes, $15 \mathrm{~m}$ baseline), where they join the regional generally flat mare (black arrows in Figure 4b). The surrounding mare surface slopes slightly down to the east (Figures $3 \mathrm{a}$ and $4 \mathrm{~b}$ ). The Cauchy 5 small shield has a total volume of $\sim 0.5 \mathrm{~km}^{3}$. Cauchy 5 is generally typical of the population of small shield volcanoes on the Moon (Figure S1; Head \& Gifford, 1980; Tye \& Head, 2013; Wöhler et al., 2006, 2007; Lena et al., 2007, 2008; Liu et al., 2018), but lies at the lower end of the diameter, height and volume ranges typical of these features (Figure S1).

Cauchy 5 displays an elongate summit pit crater (Figures 3, 4a, 5 and 6), $\sim 0.75 \times 2.5 \mathrm{~km}$ wide and $\sim 75 \mathrm{~m}$ deep, oriented in a WNW direction (Figure 5). The pit crater floor is about $65-$ $75 \mathrm{~m}$ below the rim of the pit crater and about 45-60 $\mathrm{m}$ below the elevation of the surrounding maria. This configuration is different from that of the much larger $\sim 22 \mathrm{~km}$ wide Ina small shield volcano (compare Figures 4a, b and 4c, d). At Ina, the shield summit stands more than $300 \mathrm{~m}$ above the surrounding mare surface and the summit pit crater floor is $\sim 20-50 \mathrm{~m}$ below the pit crater rim, more than $250 \mathrm{~m}$ above the surrounding mare on which the shield is constructed (Figures 4c and 4d; Qiao et al., 2017, 2019a).

One of the three major Type 1 "mound + floor" IMPs identified by Braden et al. (2014) occupies the summit pit crater of Cauchy 5 shield volcano (Figures 3 and 5; \#3 IMP in Braden et al.'s Table S1). In a manner similar to the two other largest Type 1 IMPs, Ina (\#2) and Sosigenes (\#1), the Cauchy 5 summit pit crater contains a combination of extensive mound-like deposits on the pit crater floor, and rough textured and optically immature floor and adjacent wall material (Figure 5). In addition to its similarities to Ina and Sosigenes, Cauchy 5 also shows some differences. First, both Ina and Sosigenes show a generally distinctive difference between the mare plains surrounding the pit crater/graben, and the mound and bright/rough terrain that characterize the pit crater floor (Garry et al., 2012; Braden et al., 2014; Qiao et al., 2017, 2018, 2019a). In the case of Cauchy 5, the generally elongate, tongue-depressor shape of the vent is perturbed to the west and north by an extension of the pit crater, although at a level $\sim 30-45 \mathrm{~m}$ shallower than the deepest part of the pit in the southeast (Figures 5 and 6). This configuration suggests that there may have been at least two topographic levels for lava partially filling the lava lake; a deeper one to the southeast (approximately between contours $-895 \mathrm{~m}$ and $-910 \mathrm{~m}$ in Figure 5d) and a much shallower one to the northwest (approximately between contours $-880 \mathrm{~m}$ and $-865 \mathrm{~m}$ in Figure 5d). In addition, an $\sim 750 \times 850 \mathrm{~m}, 30-35 \mathrm{~m}$ deep topographic extension/opening occurs in the northern part of the pit crater (Figure 5), characterized by 
comparable or slightly lower elevations (down to contour $-880 \mathrm{~m}$ in Figure $5 \mathrm{~d}$ ) than for the northwest part of the vent floor (Figures 3,5 and 6). This feature may have been an exit breach for flows leaving the summit pit crater lava lake, as seen in some terrestrial small shield volcanoes (e.g., Tilling, 1987).

Secondly, mound and rough terrain textures typical of the interior of the Ina and Sosigenes depressions also occur in Cauchy 5 on an $\sim 750 \times 800 \mathrm{~m}$ area on the NW rim (Figure 7), and in a $\sim 1.3 \times 1.4 \mathrm{~km}$ area to the north, within the rim depression and to its west and north (Figure 5). These distinctive morphologic occurrences and the different topographic levels that characterize the pit crater floor, are also similar to evidence for multiple levels in erupting, fluctuating and receding terrestrial lava lakes in small shield volcanoes and vent areas (e.g., Peck et al., 1979; Tilling, 1987; Wolfe et al., 1987; Tilling et al., 1987, their Figure 16.8).

Thirdly, unlike Ina and Sosigenes, smaller, pit-like Type 2 IMPs (rough and pitted terrains in small patches) occur in two broad regions on the summit rim and flanks of the Cauchy 5 small shield volcano (Figure 8): 1) an $\sim 1 \times 4 \mathrm{~km}$ broad belt on the northern shield flank, located at a distance from the topographic breach in the elongate pit crater (pink polygons in Figure 8a and local map in Figure 8c), and 2) a concentric zone adjacent to the southeastern edge of the elongate pit crater and extending up to 0.5 to $2 \mathrm{~km}$ from the pit crater rim (blue polygons in Figure 8a and local map in Figure 8d). Examination of the southeastern rim pit-type IMP region (Figure 8d) shows that it is characterized by over 70 small irregular IMP-like pits, while the northern Cauchy 5 shield flank pit-type IMP region (Figure 8c) is also populated by $\sim 70$ small irregular pits. Many of these small pits occur on the interior steep walls of depressions, immediately adjacent to the depression rim crest (Figure 8d). The two small-pit-type IMP occurrences show similar length-frequency distribution patterns (Figure 8b) (112 m mean and 96 $\mathrm{m}$ median lengths for the north flank small pits; $118 \mathrm{~m}$ mean and $94 \mathrm{~m}$ median lengths for the southeastern rim small pits) and areal density ( 14-18 pits per $\left.\mathrm{km}^{2}\right)$. We focused on all relatively large Type 2 IMP pits (>50 $\mathrm{m}$ in length) on relatively flat surfaces (a total of 65 pits; these do not include pits on the upper walls of depressions) and measured their pit depth from LROC NAC DTM topography by deriving the elevation difference between the average elevation of the surrounding surface (5-15 m exterior buffer area from the pit edge) and the minimum elevation of the pit interior. The measured pit depths (Figure $8 \mathrm{e}$ ) range from $\sim 1$ to $\sim 6 \mathrm{~m}$, with a mean pit depth of $\sim 3 \mathrm{~m}$. Virtually all pits $(95 \%)$ have depths of $<5 \mathrm{~m}$. More importantly, the pit-type IMP features seen in these two localities are very similar in morphology to those Type 2 IMPs documented in the updated Braden et al. (2014) IMP catalog (Qiao et al., 2019b) (compare the Cauchy 5 rim and flank small pit-type IMPs to occurrences \#8, 10-19, 22-25, 27-32, 34, 35, 37 , 39-40, 41-49, 51-56, 59-61, 63 and 65-70 small IMP examples in the Braden et al. (2014) list (their Table S1)). However, these small pits at Cauchy 5 are generally smaller than the Type 2 IMPs cataloged by Qiao et al. (2019b), which have a mean and median length of $275 \mathrm{~m}$ and 200 $\mathrm{m}$, respectively.

Remote sensing data provide further characterization of the Cauchy 5 small shield. Groundbased Arecibo radar observations (Campbell et al., 2010) show that the Cauchy 5 shield flank is characterized by fine-grained, block-poor materials (Carter et al., 2013; Figure S4), in contrast to the basalt bedrock-derived regolith substrate typical of surrounding regional mare deposits. Carter et al. (2013) interpreted these characteristics as possibly indicating the presence of pyroclastic deposits on the flanks of the Cauchy 5 shield volcano. LRO Diviner thermophysical mapping also shows that the surface between the Type 2 IMPs on the Cauchy 5 shield flank is 
less blocky than the highly pitted surfaces at the northern base edge of the shield (Elder et al., 2017). The Cauchy 5 small shield and the surrounding mare plains are similar in surface mineralogy (high-titanium basalts; Staid \& Pieters, 2000), suggesting a mare basalt composition comparable to that of other areas of Mare Tranquillitatis.

Mapping of reflectance at $750 \mathrm{~nm}$ and optical maturity based on Kaguya Multiband Imager (MI) spectrometer data (20 m/pixel; Ohtake et al., 2008) and the algorithm of Lemelin et al. (2015) was undertaken for the relatively extensive pits (dominantly on the interior steep walls of many depressions) at the southeastern rim of Cauchy 5 (Figure 9). These data show that these mapped small IMP-like pits are generally more reflective and optically immature than the interpit terrains and surrounding mare, similar to observations of the hummocky and blocky floor units at the interior of several large Type 1 IMPs such as Ina and Sosigenes (Strain \& El-Baz, 1980; Schultz et al., 2006; Staid et al. 2011; Garry et al., 2013; Bennett et al. 2015; Qiao et al., 2018, 2019a). In addition, these optical property maps reveal obvious reflectance and optical maturity variations among these mapped pits (noted by arrows in Figure 9).

The flat mare unit surrounding Cauchy 5 is dated to over three billion years in age (Hiesinger et al., 2011), comparable with our CSFD dating result for a $5 \times 5 \mathrm{~km}^{2}$ mare area north of Cauchy 5 (Figure S2). We performed crater-counting analyses (craters $\geq 10 \mathrm{~m}$ in diameter) on the inter-pit surface at the north edge of the Cauchy 5 small shield, where abundant small pits are observed, using LROC NAC images (Figures 10a and c). The resulting crater populations are presented in the standard cumulative (Figure 10b) and relative (Figure S3) size-frequency distribution plots (the conventional methodology utilized in the community, e.g., Crater Analysis Techniques Working Group, 1979; Fassett, 2016). For comparison, we also transferred the map of the crater count working area on the northern shield flank onto the adjacent mare surface and counted the superposed impact craters there (Figures 10a, b and d). The shield flank area shows a much lower crater density for craters $\geq 10 \mathrm{~m}$ in diameter when compared with the surrounding basaltic mare surface, especially at larger diameter ranges. Lunar chronology function (CF) and production function (PF) (Neukum et al., 2001) fitting of these shield flank craters yields a model age of hundreds of million years $(160 \mathrm{Ma})$, significantly younger than the surrounding $>3$ Ga old ancient mare reported previously (Hiesinger et al., 2011). The CSFD plot of flank craters (black crosses in Figure 10b) does not follow the isochron curve exactly, which is probably related to the fact that a lot of craters are destroyed/obscured by collapse upon impact. (Note that we do not calculate a model age from craters in the surrounding mare count area closely adjacent to the small shield (red polygon in Figure 10a) as this dating analysis suffers from both the problems associated with the small crater counting area and the very small number of impact craters used to derive the age estimate.) In summary, three different CSFD ages are derived for the Cauchy 5 small shield area: 1) 54 Ma for the Cauchy 5 pit crater interior (Braden et al, 2014), 2) 160 Ma for the Cauchy 5 shield flank and 3) at least $3000 \mathrm{Ma}$ for the mare areas adjacent to Cauchy 5 (here and in Hiesinger et al., 2011).

Utilizing this information on the setting, characteristics and apparent ages of Cauchy 5 and its surroundings, we now turn to models of the generation, ascent and eruption of magma in a small shield volcano environment in order to assess predictions that might be helpful in the interpretation of Cauchy 5's observed deposits and structures (Figures 2-7), and the population of Type 1 and Type 2 IMPs (Figures 8-10). 


\section{Models of Generation, Ascent and Eruption of Magma for Lunar Small Shield Volcanoes}

Lunar small shield volcanos are generally interpreted to be constructed from relatively loweffusion-rate, cooling-limited lava flows erupting from a centralized vent and still-active and evolving summit pit crater (e.g., Head \& Gifford, 1980; Wilson \& Head, 2017b; Head \& Wilson, 2017). In the context of dikes intruding from the mantle into the shallow crust and erupting onto the surface (Figure 1), small shields are interpreted to lie in the range between small-volume dikes that penetrate to the near-surface and stall, producing pit craters, graben and perhaps small cones (Figures 1a-c), and large-volume dikes that penetrate to the surface to produce largevolume, high-effusion rate eruptions (Figure 1f). Within this category, volumes and effusion rates can range from very low (smaller shields) to low (larger shields) (compare Figures 1d and $1 \mathrm{e})$.

The characteristics of the four eruption phases during a typical lunar mare basalt eruption (Wilson \& Head, 2018) (Figure 11A) are as follows: In Phase 1, the dike penetrates to the surface and very rapidly explosively vents the gas and foam that have accumulated at the top of the dike during its ascent. In Phase 2, the dike base continues to rise, forcing very large quantities of magma out of the vent at very high effusion rates, creating a very vigorous hawaiian fire fountain eruptive phase. During Phase 3, the dike equilibrates, accompanied by a decrease in magma rise speed and flux, and undergoes a transition from hawaiian to strombolian activity (Parfitt \& Wilson, 1995). The vast majority of the magma extruded to the surface during the eruption is emplaced during Phases 2 and 3. The volatile content of the erupted distal lava flows during Phase 3 and most of Phase 4 is very low due to their having lost volatiles during the hawaiian fire-fountain stage of Phase 3. During Phase 4, magma rise speed decreases to $<1 \mathrm{~m} / \mathrm{s}$ and the volume flux of the extruded magma decreases substantially. Due to the very much lower rise rate in Phase 4, explosive activity is confined to the strombolian bursting of large bubbles of $\mathrm{CO}$, formed by coalescence, during the slow magma ascent, of small bubbles released at great depth in the dike; shallow-nucleating volatiles (water and sulfur compounds, Rutherford et al., 2017) remain as bubbles in the magma arriving at the top of the dike, causing the extruded lava to be highly vesicular.

These four eruption phases are predicted to vary in importance and magnitude during the low-volume, low-effusion rate eruptions typical of small shield formation, particularly for the lower end of the volume range indicated for the small (5-6 km diameter), low elevation ( 40 meters), low volume $\left(\sim 0.5 \mathrm{~km}^{3}\right)$ Cauchy 5 shield. A comparison of the four eruption phases in such a low-volume, low-effusion rate small shield eruption and the more typical larger-scale mare basalt eruption is shown in Figures 11. Low-volume, low-effusion rate eruptions are dominated by Phases 1 and 4 due to the very small total volume of erupted magma and the correspondingly low effusion rate. As the dike rises from the mantle source region, gas is exsolved (e.g., Wilson \& Head, 2003; Rutherford et al., 2017) and concentrated in the dike tip, below which is bubble-rich magmatic foam, both overlying the rising magma in the remainder of the dike. During Phase 1, the dike penetrates to the surface vacuum, and the gas and magmatic foam in the upper part of the dike explosively vent to the surface. In high-effusion rate eruptions (Figure 11A), the explosion accompanying the transient gas release phase is rapidly followed by the Phase 2 eruptive phase as magma surges onto the surface. In the much lower-volume and lower-effusion rate-case of the small volume end of small shield volcanoes, the Phase 1 explosive venting at the top of the dike leaves a void into which the brecciated country rock of the dike wall can collapse (Figure 11B). As the magma below the evacuated gas and foam at the 
top of the dike then continues to rise in the dike toward the surface, the rise rate is sufficiently low (less than $5 \mathrm{~m} / \mathrm{s}$ ) that Phases 2 and 3 do not occur in a manner similar to that in large-volume eruptions. Instead, in a highly abbreviated Phase 2-3, the relatively degassed magma in the top of the dike rises into the newly formed collapsed pit and extrudes out onto the surface to form the initial layers of a small shield. As the magma rise speed decreases to less than $\sim 1 \mathrm{~m} / \mathrm{s}$, Phase 4 is initiated. Due to the very slow magma rise speed, ascending bubbles of $\mathrm{CO}$ released at great depth (Rutherford et al., 2017) have sufficient time to form, expand, rise and coalesce into slugs. Strombolian activity (bursting of coalesced gas slugs at the top of the lava lake; Blackburn et al., 1976; Ripepe et al., 2008) will be the result. However, beneath the undisturbed parts of the lava lake, relatively soluble and therefore shallow-nucleating water and sulfur compounds (e.g., Rutherford et al., 2017; Head \& Wilson, 2017) will have had time to exsolve, leading to very high vesicularity.

Four factors are important in the waning stages of a typical small-volume, small-effusion rate eruption: 1) magma rise-rate, already low due to the small volume of the eruption, continues to decrease due to the lack of additional deeper magma in the dike, 2) the low rise-rate maximizes gas exsolution in the remaining magma in the dike, causing volume expansion, 3 ) elastic forces initially holding the dike open begin to relax, contributing to closure of the dike, and 4) magma lining the walls of the dike conductively cools, further narrowing the dike and decreasing the remaining dike volume. Although these processes act at different rates, the net balance of forces tends to drive the lava lake surface upward in a piston-like manner; the very bubble-rich/vesicular magma in the lava pond and dike below are thus forced upward, filling and potentially overtopping the lake, and causing effusion of very vesicular lava out onto the small shield volcano rims and flanks. This type of late stage behavior is well documented in terrestrial small shields, pit craters and low-volume eruptions, and can result in multiple phases of lava lake rise and fall (e.g., Tilling, 1987; Tilling et al., 1987; Wolfe et al., 1987).

Continuing loss of volume from 1) dike-magma supply exhaustion, 2) dike solidification and 3 ) loss of gas volume from strombolian activity in the lava lake, results in the final recession of the lava lake floor down into the pit crater interior. In terrestrial small shield volcanoes and pit craters, the eruption comes to an end when the thermal boundary layer at the lava lake surface solidifies to a thickness sufficient to cause rising magmatic slugs to collect below the lava lake floor, instead of disrupting the surface in strombolian activity (e.g., Blackburn et al., 1976).

On the Moon, the low gravity and absence of atmosphere lead to a low overburden pressure resulting in a different behavior from that of typical terrestrial eruptions. For a given magma volatile content, lunar lava lakes will have a proportionally greater amount of bubbles forming below the solid surface. As the lunar lava lake magma continues to cool, second boiling causes further release of remaining magmatic volatiles (Wilson et al., 2019), adding to the total volume of gas. The final products from all of the gas exsolving from the magma remaining in the top of the dike and lava lake build up below the thickening lava lake floor layer, collecting as 1) gas void space (rising gas slugs trapped beneath the solidified floor), 2) very vesicular magmas (rising gas bubbles and bubble-rich magma) and 3) magmatic foams (where the vesicle content exceeds $\sim 75 \%$ of the volume). Models of the effects of these unusual lunar environmental conditions in the last stages of enhanced magmatic volatile collection below a lava lake suggest that lava lake floor flexure and cracking can result in the extrusion of magmatic foams onto the surface of the lava lake (Wilson \& Head, 2017a), a process unknown on the Earth.

The final stage of the dike emplacement event occurs at the end of Phase 4 activity, when 
the lava lake and underlying dike cool and solidify, a process lasting up to several years. During this period, the remaining cooling magma in the top of the dike and lava lake will undergo an $\sim 10 \%$ volume reduction due to solidification, and the lava lake floor will adjust to this volume decrease by sagging and lowering accordingly.

The fate of any highly bubble-rich/vesicular magma that is forced up and out of the lava lake and flows out onto the small shield volcano flanks is predicted to be the following. First, plates of the partly solidified lava lake floor will be rafted out onto the small shield rim and flanks. Secondly, the upper surfaces of the extremely vesicular flows will undergo a mild explosive activity into the overlying vacuum to form a meters-thick layer of "auto-regolith" (Head \& Wilson, 2019), a carpet of explosively ruptured bubble wall fragments and glass shards that protects the underlying flow from further explosive disruption (Wilson et al., 2019). As the very bubble-rich/vesicular lava flows on the flanks of the shield continue to cool below the autoregolith layer, second boiling causes the exsolved bubbles and foams to continue to form, grow, and to migrate laterally and rise vertically; shear from final flow emplacement and cooling can locally break down bubbles and form voids beneath the cooling and thickening auto-regolith and solidified flow surface. As the flank flows continue to cool, second boiling of the cooling magma at the base of the flow is predicted to cause new gas exsolution, bubble growth, flow inflation and migration of bubble and foam-rich magma laterally and vertically in the flow (e.g., Wilson et al., 2019). This late-stage process adds to the volume of very vesicular foam and gas pockets below the cooling and thickening flow surface. Final solidification of flank flows is predicted to result in a three-layer stratigraphy (Wilson et al., 2019; Head \& Wilson, 2019): a) an upper, meters-thick, auto-regolith layer of glassy bubble-wall shards above a lower, welded, pyroclast layer, grading down into b) a medial, many meters-thick, highly vesicular-foamy layer with distributed linear and circular pockets of voids formed by bubble-foam collapse and gas migration and collection, and c) a lower layer of solidified degassed magma chilled against the underlying pre-eruption surface.

These theoretical analyses of the nature of low-volume, low-effusion rate small shield volcano eruptions on the Moon (Figure 11B) (e.g., Wilson \& Head, 2017a, 2018, 2019; Head \& Wilson, 2017; Rutherford et al, 2017; Wilson \& Head., 2018) provide a framework of predictions for assessing and interpreting the nature, structure, morphology and history of the Cauchy 5 small shield volcano.

\section{Synthesis of Cauchy 5 Small Shield Volcano Emplacement History and Setting for Type 1 and 2 IMPs}

We now revisit the major characteristics of the Cauchy 5 small shield volcano outlined in Section 2 (illustrated in Figures 2-10 and S2-3) and assess these in the context of the models of the generation, ascent and eruption of lunar magmas, and the several phases in their emplacement, described above (Figure 11B), leading to the following interpreted steps in the geologic history of the Cauchy 5 small shield volcano and its associated Type 1 and Type 2 IMPs (Figures 12-14).

1) Formation and upward propagation of magma-filled, convex-upward crack and dike from the source region in the lunar mantle: The volume of magma in the dike is small relative to that in typical mare basalt eruptions. Magma overpressurization and the mantle-melt density contrast cause the dike to rise buoyantly into the overlying less-dense anorthositic crust where the change to negative buoyancy results in a decrease in propagation velocity (Figure 12a). As 
the dike rises from the source region, gas exsolves in the propagating low-pressure zone in the crack forming the tip of the dike (e.g., Wilson \& Head, 2003), and collects as free gas in the upper part of the dike and as a zone of gas bubbles in the region below the gas and above the bulk of the magma.

2) Initial arrival and penetration to the surface of the convex-upward, WNW-trending dike from depth in the mantle: Eruption Phase 1: As the relatively slowly rising dike decreases further in propagation velocity as more of it enters the low-density crust, the dike tip reaches the lunar surface and erupts into the vacuum, resulting in explosive venting of the gas and magmatic foam in the top of the dike (Figures $11 \mathrm{~b}$ and 12b). This gas and explosively disrupted foam of the Cauchy 5 eruption lasts only a few minutes; disrupted foam bubble wall pyroclasts are very widely dispersed in the region surrounding the vent. The explosive venting creates a large void space in the slowly rising upper few hundred meters of the dike; dike wall material shattered by the explosive venting collapses into the void to create an elongate $(\sim 0.75 \times 2 \mathrm{~km})$ surface collapse crater along the strike of the dike (Figure 13a).

3) Slow rise of relatively degassed magma in the top of the dike: Abbreviated Eruption Phase 2/3: As the magma continues to rise in the dike, the largely degassed magma (previously below the now-vented gas and magmatic foam dike tip area; Figure 12a) slowly rises and extrudes out onto the surface, forming the initial layers of the small shield as it builds up around the vent (Figure 12c). Predicted low magma rise speeds and volume fluxes support the interpretation that this initial phase will consist of cooling-limited flows (Head \& Wilson, 2017) extending a few kilometers radially away from the vent (Figure 13b). The low magma volumes and rise rates compared with more typical mare basalt eruptions, and the largely degassed nature of the magma, result in extremely abbreviated eruption Phases 2 and 3 (Figure 11B).

4) Strombolian activity-vesicular flow eruption phase: Phase 4: Newly arrived gascontaining magma from below the gas-depleted upper part of the dike enters the lowoverburden-pressure upper several kilometers of the dike, exsolving gas as it rises (Rutherford et al., 2017) (Figure 12d). The very low magma rise rate maximizes the amount of gas exsolution, particularly of $\mathrm{CO}$ released at great depths, bubble rise, growth and coalescence, and causes episodic strombolian activity (Blackburn et al., 1976) in the summit pit crater. The cooling thermal boundary layer at the top of the lava lake floor begins to form and stabilize, but is disrupted by the rising and bursting gas slugs of the strombolian activity.

5) Lava lake inflation and overflow: Phase 4: As the magma rise rate in the dike at depth decreases toward zero, signaling the final stages of the eruption (Figure 11B), other forces come into play to cause fluctuation of the lava lake level. A combination of a) increasing dike magma volume due to shallow-release gas bubble formation causing magma expansion, and b) relaxation of elastic forces initially holding the dike open, force the extremely bubble-rich magma up into the pit crater, over the rim and onto the flanks of the nascent small shield volcano (Figures 12e and 13c).

6) Emplacement of very highly vesicular/foamy flanking flows: Phase 4: In this latter stage of Phase 4, the lava lake floor rises and lava spills out over the rim of the small shield, producing a second stage of flanking flows (Figure 12e). In contrast to the initial stage of largely volatile depleted flows, the emplaced magma is now composed of the extremely bubble-rich foamy lava that has collected in the lava lake below the cooling crust. Portions of the cooled lava lake floor crust are disrupted and emplaced on the shield flanks. The newly erupted upper layers of the 
extremely vesicular/foamy lava flows are exposed to the lunar surface vacuum. They decompress explosively to form a meters-thick layer of "auto-regolith", a carpet of popped bubble wall fragments and glass shards (Head \& Wilson, 2019). The unusual remote sensing properties of the Cauchy 5 flanking flow surfaces (anomalously finer grained, block poor; Figures 9 and S4) are attributed to the glassy auto-regolith layer produced by this explosive decompression of the upper vesicle-rich layer of the extruded flows as they encounter the surface vacuum. The relatively optically immature and blockier nature of the flanking Type 2 IMP pit walls and floors (Figures 8 and 9) are interpreted to be due to post-flow-emplacement/cooling impact crater events; these cause collapse of voids of various scales and shapes, and different ages (consistent with the observed optical maturity variations), exposing fresh, more coherent material from the underlying parts of the flow.

7) Termination of the eruption and recession of the lava lake floor into the pit crater: As the magma rise rate in the dike decreases to zero, signaling the end of the eruption, continued degassing of magma in the lava lake decreases the total volume of magma in the dike and lava lake, causing recession (Figure 12f) and magma withdrawal into the pit crater, leading ultimately to stabilization of the lava lake floor. This is enhanced by the volume reduction of the magma in the deeper parts of the dike as it cools and solidifies. The lava lake surface crust continues to thicken, further suppressing the strombolian eruption bursts caused by rising magmatic gas slugs (Figure 12g). These bursts eventually cease as all of the deep-sourced gas is exhausted.

8) Drainback of portions of the rim lavas into the crater interior: As the lava lake floor deflates and subsides into the pit crater, portions of the still-cooling lava flow on the rim drain back into the pit crater interior (Figure 13d), leaving islands of cooled lava and auto-regolith, interspersed with regions where the chilled upper layer of the flow has drained back into the pit crater, exposing the very bubble-rich/vesicular parts of the flow (Figures 5-7). This leads to unusual patterns and topography of the exposed and bubble/foam-rich interior of the flow, and possible degassing of foams to form mounds and depressions.

9) Eruption aftermath: Pit crater interior: In this post-eruption period, the lava lake in the pit crater interior begins to undergo final cooling, degassing and solidification (Figure 12h). The upper cooling thermal boundary layer (the macro and micro-vesicular lava lake floor) continues to thicken and solidify, inhibiting further strombolian activity and gas loss to the surface. The most recently arrived magma in the top of the dike continues to degas under the thickening lava lake floor, exsolving significant quantities of gas bubbles that rise and collect as a magmatic foam below the lava lake crust. As the lava lake cools further, second boiling (Wilson et al., 2019) contributes additional volatiles. In contrast to terrestrial eruptions at this stage, the low lunar gravity and low overburden pressure together favor extensive gas production, bubble growth and foam development in the lava lake. This excess volume can cause flexing and fracturing of the cooling and thickening lava lake floor crust. Models of this configuration in other pit craters predict that this flexing and cracking can result in the extrusion of portions of the underlying magmatic foams out onto the lava lake floor to produce magmatic foam mounds and coalesced deposits (Wilson \& Head, 2017a; Qiao et al., 2018, 2019a) (Figures 12h and 13e). Evacuation of foams to the surface can result in additional subsidence and/or production of large void spaces below the flexing thermal boundary layer, depending on its local thickness and rheology. Final solidification of the lava lake will cause additional subsidence in the lava lake interior (Figure 12i). 
10) Predicted final substrate target properties: Pit crater interior: On the basis of this interpreted Cauchy 5 eruption history (Figures 12a-i and 13a-e), following the end of the eruption, the interior of the pit crater should be characterized by a cross-section (Figure 14a) consisting of: 1) a solidified very highly macro- and micro-vesicular boundary layer of the lava lake floor, superposed by coalesced extrusions of magmatic foam (topped by a meters-thick layer of auto-regolith). 2) An underlying layer of coalesced bubbles and foams that have risen in the lava lake and solidified beneath the lava lake floor. Bubbles and foams should dominate the top of this underlying layer, producing extreme macro and micro-vesicularity. This layer should also contain large meters-scale voids formed from gas slugs that have risen in the dike and lake and become trapped below the lava lake crust. Additional large voids might be anticipated from space left by foams leaking to the surface through flexing and cracking of the lava lake surface layer. 3) Lower layers of progressively degassed lavas from which exsolved bubbles have risen upward in the cooling lava lake. This distinctive substrate (Figure 14a) lies in stark contrast to the initial solid lava substrate predicted to be typical of nominal Phase 2 distal lava flows (Figure 11A) representing the majority of the lunar mare surfaces (Wilson \& Head, 2017b; Head \& Wilson 2017, 2019).

11) Eruption aftermath: Flanking bubble-rich/vesicular flows: At the end of the eruption, the very bubble-rich/vesicular flows on the flanks of the volcano continue to cool (Figure 14b). Exsolved bubbles and foams continue to migrate laterally and rise vertically; shear from the final flow emplacement and cooling can locally break down bubbles and form voids beneath the cooling and thickening auto-regolith and solidified flow surface. As the flank flows continue to cool, second boiling (Wilson et al., 2019) of the cooling magma toward the base of the flow causes new gas exsolution, bubble growth, flow inflation and migration of bubble and foam-rich magma laterally and vertically in the flow, adding to the very vesicular foam and gas pockets below the cooling and thickening flow surface. If pressure in local gas pockets and cavities exceeds the overburden pressure of overlying auto-regolith layer and the evolving mechanical strength of the welded pyroclast layer at the base of the auto-regolith layer, there is the potential for formation of local explosion craters. This final inflation activity should also contribute to the hummocky topography of the final flow surface (Figure $3 \mathrm{~d}$ ).

12) Predicted final substrate target properties: Flanking bubble-rich/vesicular flows: Final solidification of the flank flows is predicted to result in a three-layer stratigraphy (Figure 14b): a) an upper, meters-thick, auto-regolith layer of glassy bubble-wall shards above a lower, welded, pyroclast layer, grading down into b) a medial, many meters-thick, highly vesicular-foamy layer with distributed linear and circular pockets of voids formed by bubble-foam collapse and gas migration and collection, and c) a lower layer of solidified degassed magma chilled against the underling flow.

13) Subsequent history of Cauchy 5 small shield volcano: The interpreted multi-stage eruption history of the Cauchy 5 small shield volcano outlined above (Figures 12a-i and 13a-e) sets the stage for its post-solidification geologic history, consisting largely of superposed impact cratering events and regolith development and thickening.

We now use this synthesis as a basis for discussion of several outstanding issues, including 1) the relationship between the IMPs on the pit crater floor and those on the shield volcano rim and flank, 2) the nature and evolution of the impact generated regolith, 3) the influence of the substrate on the superposed impact crater population and 4) the estimated absolute age of the emplacement of the Cauchy 5 small shield volcano. 


\section{Discussion}

\subsection{Insights into the Origin of IMPs: Cauchy 5 Small Shield Volcano as a Guide}

We now proceed to compare 1) the nature of the substrate on the Cauchy 5 pit crater floor (Figure 14a) and the small-shield flank (Figure 14b) and 2) the processes of impact cratering and regolith formation subsequent to edifice formation and cooling, in order to try to account for the major characteristics of the Type 1 and Type 2 IMPs. For the pit crater floor, these characteristics are: 1) the rough and relatively immature nature of portions of the floor, 2) the meniscus-like morphology and optically relatively more mature properties of the extensive lower albedo mound-like areas, and 3) the CSFD-derived age of 58 Ma. For the small shield flanks these characteristics are: 1) the size, shape, depth and areal distribution of the pits, and their relative, but variable, optical immaturity, 2) the fine-grained, block-poor nature, topography and morphology of the lower albedo shield flanks in which the pits are contained, and 3) the $\sim 160$ Ma CSFD age for the shield flanks, compared with the $>3000 \mathrm{Ma}$ age of the surrounding maria. The Type 1 IMP mound and floor deposits in the summit pit crater are interpreted to have formed during the final phase of the emplacement of the edifice. The Type 2 small pit IMPs on the shield volcano flanks could have formed in part from late-emplacement-stage explosion craters, but the majority are interpreted to have formed subsequently, as the flanking void-rich flows were subjected to impact cratering at a variety of scales and ages.

\subsection{Nature of the Initial Substrate at Cauchy 5 Small Shield Volcano and Influence on the Formation of Regolith and Type 2 IMPs}

Exploration and characterization of the lunar regolith overlying mare basalt lava flows by the Apollo 11, 12, 15 and 17 missions showed that it consists largely of a soil layer composed of mechanically fragmented solid lava flows (McKay et al., 1991; Lucey et al., 2006). Initial impact fragmentation produces optically immature bedrock blocks and rocky soils (Figure 15); subsequent impact events at all scales reduce the grain size, increase the proportion of glassy agglutinates, thicken the regolith layer and create an optically more mature surface layer (Lucey et al., 2006). As the regolith thickness increases, impact craters that penetrate through the regolith into the underlying solid basalt substrate become more infrequent. The morphology of these larger crater interiors and the occurrences of blocks in fresh craters can be used to estimate the thickness of the regolith layer (e.g., Quaide and Oberbeck, 1968; Qiao et al., 2016), and radiometric dating of the basalt lava flows at the Apollo landing sites can then provide an estimate of regolith growth rates that can be extrapolated to unsampled mare areas using crater morphology (e.g., Di et al., 2016).

These estimates of thickness and characteristics are, however, predicated on the assumption that the initial substrate on which the impact generated regolith is developed consists of solid basaltic lava flows (Figure 15), a good assumption for the geologic setting of the Apollo 11, 12, 15 and 17 landing sites. On the basis of our analysis and characterization of the Cauchy 5 small shield volcano Phase 4 volatile-rich magma behavior, the initial, post-emplacement/cooling Cauchy 5 pit floor and flank deposits (Figures 14a and b) are significantly different from the typical solid basalt flow surfaces on which regolith developed at the Apollo mare landing sites (Figure 15).

How will these differences influence the development of regolith? The partitioning of energy in impact cratering events provides a framework for addressing this question (Gault et al., 
1968). In solid mare basalt substrates (Figure 15), the kinetic energy of impact is partitioned primarily into rock fracturing, fragmentation and lateral ejection; seismic energy is efficiently radiated away from the sub-impact point due to the solid nature of the substrate. As regolith thickness grows, the ratio of energy expended in fracturing/fragmentation relative to ejection decreases and seismic energy is attenuated (relative to bedrock) by the increasing thickness of the more porous regolith.

In contrast, impact energy partitioning in very porous, vesicular, foamy and void-rich substrates (Figure 14) is predicted to be very different (e.g., Kadono, 1999; Flynn et al., 2015; Okamoto \& Nakamura, 2017; Housen et al, 2018; Head \& Ivanov, 2019; Ivanov \& Head, 2019). A significant percentage of the impact kinetic energy is now partitioned into crushing and collapse of the vesicles and voids, favoring vertical penetration of the projectile and vertical growth of the cavity, rather than lateral ejection (the well-known aerogel effect). Impact craters in vesicular/foamy substrates are thus predicted to be deeper and less wide than analogous events in a solid basaltic substrate; corresponding subdued lateral emplacement of ejecta is also predicted. In cases where larger subsurface voids exist (Figure 14) (see also Robinson et al., 2012), superposed impacts are predicted to cause fragmentation and collapse of layers overlying the voids, and exposure of fresh materials in the collapse-crater walls. Seismic energy attenuation in vesicular/foamy substrates is maximized, due to the high abundance of pore space.

Application of these principles to the Cauchy 5 small shield volcano deposits (Figure 14) results in the following interpretations. Superposed impact crater morphology and morphometry, as well as regolith buildup, are predicted to be significantly influenced by the multi-scale and abundant void space (Figure 16) (Head \& Ivanov, 2019; Ivanov \& Head, 2019). Energy partitioning will favor production of relatively smaller, irregularly-shaped deeper craters, less lateral ejection, and the drainage of fragmented material down into the underlying void spaces below and adjacent to the crater. Impact-induced seismic shaking in the vicinity of the event from this and other impact events (Yasui et al., 2015; Qiao et al, 2017) will enhance the seismicsifting and drainage of fragmental down into the subsurface void space, helping to perpetuate the optical immaturity of the newly exposed rocky material. These unusual properties of superposed crater formation, and regolith evolution and drainage, may render some impact craters difficult to recognize.

The pit crater floor rough unit is predicted to be superposed by coalesced extrusions of magmatic foam dominated by abundant micro-vesicularity (Figure 14a) and an upper layer of explosively disrupted glassy vesicle walls that builds a meters-thick auto-regolith layer and inhibits the further disruption of the underlying extruded foams (Head \& Wilson, 2019). The enhanced viscosity of the extruded foams results in a meniscus effect at the mound margins, in contrast to the underlying rough lava lake floor substrate. Craters subsequently superposed on the mounds (Figure 16a) are predicted to first encounter the meters-thick auto-regolith layer and then the underlying foam layer, resulting in variable energy partitioning and potentially resulting in funnel-shaped craters.

These distinctive substrates (Figure 14a) lie in stark contrast to the initial solid lava substrate predicted to be typical of nominal Phase 2 distal lava flows representing the majority of the lunar mare surfaces (Langevin \& Arnold, 1977; Hörz, 1977; Wilcox et al., 2005) and are not readily interpretable in the context of traditional solid bedrock regolith growth models (Figure 15). Instead, these combined considerations of initial substrate characteristics and the effects on superposed impacts and regolith buildup predict that: 1) the rough floor unit should have unusual 
superposed craters (Figure 16b), regolith buildup will be inhibited due to seismic sifting and drainage, and optical immaturity should be prolonged for much greater durations due to the continued exposure of fresh rock material by regolith drainage; 2) the mound unit should begin with an optically more mature auto-regolith layer dominated by glassy bubble wall fragments, an underlying magmatic foam layer overlying the crater floor, and unusually shaped superposed impact craters whose properties are dominated by vertical crushing, rather than lateral ejection, and more rapid degradation of craters than on normal solid mare basalt regoliths.

The predicted characteristics of the bubble-rich/vesicular shield flanking flow units (Figure 14b) provides an additional contrast to both the pit crater floor (Figure 14a) and the solid mare basalt substrate (Figure 15) predictions. Impact craters forming in the three-layer stratigraphy (Figure 14b) will initially encounter an upper, meters-thick, auto-regolith layer of glassy bubblewall shards above a lower, welded, pyroclast layer. This grades down into a medial, metersthick, highly vesicular-foamy layer with distributed linear and circular pockets of voids formed by bubble-foam collapse and gas migration and collection from initial flow emplacement and second boiling during solidification. Small superposed impacts (Figure 16c) will create relatively subdued craters in the auto-regolith layer that will degrade rapidly. Larger impact events will penetrate through this fragmental layer, encountering a layer of laterally varying porosity. Response to these cratering events (Figure 16c) is predicted to range from: 1) impact-induced mechanical collapse of surface material into underlying layer void space, forming pits with a relatively immature deposit on the floor and exposing adjacent fresh layers in the pit walls (e.g., Figure 17a); 2) shock-induced shattering of bubble and foam walls and collapse of overlying layers producing depressions and pits that should be highly irregular in shape (e.g., Figure 17b) due to a) heterogeneities in bubble size and spatial distribution and b) variations in shock wave magnitudes and symmetries; 3 ) a variety of craters with non-traditional morphologies, degradation states and morphometries due to lateral and vertical variations in size and distribution of layer pore space and the effects on energy partitioning (e.g., Figure 17c); and 4) craters formed in rafted lava plates and less vesicular parts of the flank flow that are predicted to be more similar to those formed in solid bedrock with a modest thickness of regolith (the autoregolith in the case of the flank flows). Even larger impact events will penetrate through the entire flanking flow into the underlying solid basalt shield and regional mare substrate deposits. Intermediate to larger-scale craters that penetrate through the porous layer are predicted to expose the porous layer in the upper part of their walls (e.g., Figure 17d). Examples of this diversity of predicted flanking flow morphologies observed at Cauchy 5 are shown in Figures $16 \mathrm{c}$ and 17.

In this scenario, the majority of the pits observed on the Cauchy 5 shield flanks would form throughout the post-emplacement history of the flank flows. Thus, the walls and floors of the pits are expected to show a range of optical maturity related to the time since their formation and the reduction in the initially steep slopes of the pit walls. The wide range of pit optical maturity levels observed supports this hypothesis and suggests that the vast majority of the pits did not form at the time of flank flow emplacement. Indeed, few pits are observed that have maturity levels indistinguishable from those of the adjacent inter-pit regolith surface (Figure 9).

\section{Summary and Conclusions}

We combined the predictions of a lava flow emplacement model and observation of the characteristics of Cauchy 5 to interpret: 1) the elongate pit crater to be the consequence of the 
initial venting of the dike magma to the surface and collapse of the top of the dike and adjacent substrate into the resulting void, 2) the low volume of the shield to be related to the low-volume, low-rise-rate nature of the dike emplacement event, 3) the flank flows containing small Type 2 $I M P s$ to be related to the overtopping of gas-bubble-rich magma from the lava lake onto the small shield flanks, and formation and migration of volatiles during bubble-rich/vesicular flow emplacement and its subsequent cooling, second boiling, and bubble migration to form gas-rich pockets and voids that collapsed due to subsequent impacts, 4) the mound-like unit on the pit crater floor to be related to the final stages of the activity in the lava lake pit crater interior: the cooling thermal boundary layer of the lava lake floor, the formation of magmatic foams below this layer, and the cracking and extrusion of foams onto the solidifying lava lake floor.

The unusual optical and radar remote sensing properties of the Cauchy 5 flanking flow surfaces (anomalously finer grained, block poor) are attributed to the glassy auto-regolith layer produced by the explosive decompression of the upper vesicle-rich layer of the extruded flows as they encounter the surface vacuum. The relatively optically immature and blockier nature of the flanking Type 2 IMP pit walls and floors are interpreted to be due primarily to subsequent impact crater events in the post-flow emplacement/cooling; these cause collapse of voids of different scales and shapes and different ages, exposing fresh, more coherent materials from the underlying parts of the flow.

We conclude that this small-volume, low-effusion-rate eruption scenario may help explain the relationship between the characteristics and mode of formation of Type 1 (large) IMPs (pit crater floor evolution and extrusion of foams) and Type 2 (small) IMPs (very bubblerich/vesicular flank flows and the formation and evolution of void space within the flows). The unusual hybrid association of Type 1 and Type 2 IMPs at Cauchy 5 is thought to be related to its small size, caused by its low-volume, low-effusion-rate eruption, and the suppression of the volumetrically significant Phases 2 and 3 characteristic of larger eruptions.

Remaining incompletely explained are: 1) the superposed CSFD and absolute model ages interpreted to represent an age of $\sim 58 \mathrm{Ma}$ for the pit crater and $\sim 160 \mathrm{Ma}$ for the flank flows, both ages seemingly inconsistent with the age of regional surrounding flows (>3000 Ma); 2) the morphologically crisp and optically immature aspects of IMPs, and 3) why the small Type 2 IMPs on the flanks of Cauchy 5 are smaller $(\sim 115 \mathrm{~m})$ than the Type 2 IMPs in the rest of the population elsewhere on the Moon ( $275 \mathrm{~m}$ average length).

We speculate that the discrepancy in CSFD-derived ages may be due to substrate target properties: the very porous nature of the pit crater floor substrate and the auto-regolith on the shield flanks. Kinetic energy partitioning of projectiles impacting into the vesicle-foam-void-rich substrate will favor the vertical crushing and collapse of voids rather than brittle deformation and lateral ejection; these factors influence both the resulting size of craters (smaller, thus net younger CSFD ages) and the degradation state (changing the fundamental nature of the diffusion-dominated landscape degradation models (e.g., Fassett \& Thomson, 2014)). Craters formed in the incoherent upper layer of the auto-regolith-covered flank flows will degrade faster and thus not be represented in CSFD-derived ages. Although a conclusive link to these factors has yet to be demonstrated, we infer that these observations favor an age for Cauchy 5 small shield volcano formation closer to that of the surrounding maria (>3 Ga) than to formation in the last several tens of millions of years. 
Finally, the occurrence of Type 2 (small) IMPs at Cauchy 5 provides evidence that other Type 2 IMPs elsewhere on the Moon may be linked to Phase 4 lava flow emplacement, with its relatively enhanced volatile content and vesicle/foam/void formation. We speculate that the larger size of Type 2 IMPs in the dozens of occurrences scattered across the lunar maria (average length $\sim 275 \mathrm{~m}$ compared with $\sim 115 \mathrm{~m}$ for Cauchy 5 flanks) may be explained by Phase 4 activity in the much thicker inflated bubble-rich/vesicular flows typical of more common large-volume eruptions. Phase 4 lava flow emplacement, and subsequent inflation and second boiling in much thicker flows, should favor development of locally larger void spaces and their subsequent collapse by impact events.

These conjectures can be tested by further analysis of the IMP population, and experimental and observational studies of the nature of impact cratering into porous and incoherent media, and the subsequent crater degradation.

\section{Acknowledgments}

This work is partly supported by the National Natural Science Foundation of China (Nos. 41703063, 11941001 and 41972322), a Pre-research Project on Civil Aerospace Technologies No. D020205 funded by CNSA and Qilu (Tang) Young Scholars Program of Shandong University, Weihai (2015WHWLJH14). JWH gratefully acknowledges financial support from the NASA Lunar Reconnaissance Orbiter (LRO) Mission, Lunar Orbiter Laser Altimeter (LOLA) Experiment Team (Grants NNX11AK29G and NNX13AO77G) and the NASA Solar System Exploration Research Virtual Institute (SSERVI) grant for Evolution and Environment of Exploration Destinations under cooperative agreement number NNA14AB01A at Brown University. LW thanks the Leverhulme Trust for support through an Emeritus Fellowship. All original LROC data can be retrieved from the LROC PDS archive (http://wms.lroc.asu.edu/lroc/search), all Arecibo data can be found in the NASA Planetary Data System Geosciences Node (https://pds-geosciences.wustl.edu/missions/sband/index.htm), all original Kaguya/SELENE Multiband Imager data are archived at SELENE Data Archive (https://darts.isas.jaxa.jp/planet/pdap/selene/). The pit measurement and crater count data are accessible at http://www.planetary.brown.edu/html_pages/data.htm

\section{References}

Barker, M. K., Mazarico, E., Neumann, G. A., Zuber, M. T., Haruyama, J., \& Smith, D. E. (2016). A new lunar digital elevation model from the Lunar Orbiter Laser Altimeter and SELENE Terrain Camera. Icarus, 273, 346-355.

http://dx.doi.org/10.1016/j.icarus.2015.07.039

Bennett, K. A., Horgan, B. H. N., Bell, J. F., III, Meyer, H. M., \& Robinson, M. S. (2015). Moon Mineralogy Mapper investigation of the Ina irregular mare patch. 46th Lunar and Planetary Science Conference, Lunar and Planetary Institute, The Woodlands, Texas, abstract \#2646.

Blackburn, E. A., Wilson, L. \& Sparks, R. S. J. (1976) Mechanisms and dynamics of strombolian activity, Journal of the Geological Society, 132, 429-440. https://doi.org/10.1144/gsjgs.132.4.0429

Braden, S. E., Stopar, J. D., Robinson, M. S., Lawrence, S. J., van der Bogert, C. H., \& Hiesinger, H. (2014), Evidence for basaltic volcanism on the Moon within the past 100 million years. Nature Geoscience, 7(11), 787-791. https://doi.org/10.1038/ngeo2252 
Carter, L. M., Hawke, B. R., Garry, W. B., Campbell, B. A., Giguere, T. A., \& Bussey, D. B. J. (2013). Radar observations of lunar hollow terrain. 44th Lunar and Planetary Science Conference, Lunar and Planetary Institute, The Woodlands, Texas, abstract \#2146. Campbell, B. A., Carter, L. M., Campbell, D. B., Nolan, M., Chandler, J., Ghent, R. R., et al. (2010). Earth-based 12.6-cm wavelength radar mapping of the Moon: New views of impact melt distribution and mare physical properties. Icarus, 208(2), 565-573.

https://doi.org/10.1016/j.icarus.2010.03.011

Crater Analysis Techniques Working Group (1979). Standard techniques for presentation and analysis of crater size-frequency data. Icarus, 37(2), 467-474. https://doi.org/10.1016/00191035(79)90009-5

Di, K., Sun, S., Yue, Z., \& Liu, B. (2016). Lunar regolith thickness determination from 3D morphology of small fresh craters. Icarus, 267, 12-23. https://doi.org/10.1016/j.icarus.2015.12.013

Elder, C. M., Hayne, P. O., Bandfield, J. L., Ghent, R. R., Williams, J. P., Donaldson Hanna, K. L., \& Paige, D. A. (2017). Young lunar volcanic features: Thermophysical properties and formation. Icarus, 290, 224-237. https://doi.org/10.1016/j.icarus.2017.03.004

Fassett, C. I., \& Thomson, B. J. (2014). Crater degradation on the lunar maria: Topographic diffusion and the rate of erosion on the Moon. Journal of Geophysical Research: Planets, 119, 2255 - 2271. https://doi.org/10.1002/2014je004698

Fassett, C. I. (2016). Analysis of impact crater populations and the geochronology of planetary surfaces in the inner solar system. Journal of Geophysical Research: Planets, 121(10), 19001926. https://doi.org/10.1002/2016JE005094

Flynn, G. J., Durda, D. D., Patmore, E. B., Clayton, A. N., Jack, S. J., Lipman, M. D., \& Strait, M. M. (2015). Hypervelocity cratering and disruption of porous pumice targets: Implications for crater production, catastrophic disruption, and momentum transfer on porous asteroids. Planetary and Space Science, 107, 64 - 76. https://doi.org/10.1016/j.pss.2014.10.007

Garry, W., Robinson, M., Zimbelman, J., Bleacher, J., Hawke, B., Crumpler, L., et al. (2012), The origin of Ina: Evidence for inflated lava flows on the Moon, Journal of Geophysical Research: Planets, 117, E00H31. https://doi.org/10.1029/2011JE003981

Garry, W. B., Hawke, B. R., Crites, S., Giguere, T., \& Lucey, P. G. (2013). Optical maturity (OMAT) of Ina 'D-Caldera', the Moon. 44th Lunar and Planetary Science Conference, Lunar and Planetary Institute, The Woodlands, Texas, abstract \#3058.

Gault, D. E., Quaide, W. L., \& Oberbeck, V. R. (1968). Impact cratering mechanics and structure. In B. M. French \& N. M. Short (Eds.), Shock Metamorphism of Natural Materials, (pp. 87-100). Baltimore, MD.: Mono Press.

Head, J., \& Gifford, A. (1980). Lunar mare domes: Classification and modes of origin. The Moon and the Planets. 22, 235-258. https://doi.org/doi:10.1007/BF00898434

Head, J. W., \& Ivanov, B. A. (2019). Ina Irregular Mare Patch (IMP): New insights from observations of superposed impact craters, The 10th Moscow Solar System Symposium, Space Research Institute, Moscow, Russia, abstract \#MS3-PS-32.

Head, J. W., \& Wilson, L. (1992). Lunar mare volcanism: Stratigraphy, eruption conditions, and the evolution of secondary crusts. Geochimica et Cosmochimica Acta, 56(6), 2155-2175. https://doi.org/10.1016/0016-7037(92)90183-J

Head, J. W., \& Wilson, L. (2017). Generation, ascent and eruption of magma on the Moon: New insights into source depths, magma supply, intrusions and effusive/explosive eruptions (Part 2: 
Predicted emplacement processes and observations). Icarus, 283, 176-223. https://doi.org/10.1016/j.icarus.2016.05.031

Head, J. W. \& Wilson, L. (2019). Rethinking lunar mare basalt regolith formation: New concepts of lava flow protolith and evolution of regolith thickness and internal structure. 50th Lunar and Planetary Science Conference, Lunar and Planetary Institute, The Woodlands, Texas, abstract \#2532.

Henriksen, M. R., Manheim, M. R., Burns, K. N., Seymour, P., Speyerer, E. J., Deran, A., et al. (2017). Extracting accurate and precise topography from LROC narrow angle camera stereo observations. Icarus, 283, 122-137. https://doi.org/10.1016/j.icarus.2016.05.012

Hiesinger, H., Head, J. W., Wolf, U., Jaumann, R., \& Neukum, G. (2011). Ages and stratigraphy of lunar mare basalts: A synthesis. Geological Society of America Special Papers, 477, 1-51. https://doi.org/10.1130/2011.2477(01)

Hörz, F. (1977). Impact cratering and regolith dynamics. Physics and Chemistry of the Earth, 10, 3-15. https://doi.org/10.1016/0079-1946(77)90003-9

Housen, K. R., Sweet, W. J., \& Holsapple, K. A. (2018). Impacts into porous asteroids. Icarus, 300, 72-96. https://doi.org/10.1016/j.icarus.2017.08.019

Ivanov, B. A., \& Head, J. W. (2019). Impacts into magmatic foam and the age of irregular mare patches: Experimental data, interpretations, and outstanding questions, 50th Lunar and Planetary Science Conference, Lunar and Planetary Institute, The Woodlands, Texas, abstract \#1243.

Langevin, Y., \& Arnold, J. R. (1977). The evolution of the lunar regolith. Annual Review of Earth and Planetary Sciences, 5(1), 449-489. https://doi.org/10.1146/annurev.ea.05.050177.002313

Lemelin, M., Lucey, P. G., Song, E., \& Taylor, G. J. (2015). Lunar central peak mineralogy and iron content using the Kaguya Multiband Imager: Reassessment of the compositional structure of the lunar crust. Journal of Geophysical Research: Planets, 120(5), 869-887. https://doi.org/10.1002/2014je004778

Lena, R., Wöhler, C., Phillips, J., Wirths, M., \& Bregante, M. T. (2007). Lunar domes in the Doppelmayer region: Spectrophotometry, morphometry, rheology, and eruption conditions. Planetary and Space Science, 55(10), 1201-1217. https://doi.org/10.1016/j.pss.2007.01.007

Lena, R., Wöhler, C., Bregante, M. T., Lazzarotti, P., \& Lammel, S. (2008). Lunar domes in Mare Undarum: Spectral and morphometric properties, eruption conditions, and mode of emplacement. Planetary and Space Science, 56(3), 553-569. https://doi.org/10.1016/j.pss.2007.11.010

Liu, J., Li, C., Wang, W., Zeng, X., Mu, L., \& Yang, Y. (2019). Extraction of lunar domes from Chang'E-2 data with new method. Icarus, 321, 29-33. https://doi.org/10.1016/j.icarus.2018.10.030

Lucey, P., Korotev, R. L., Gillis, J. J., Taylor, L. A., Lawrence, D., Campbell, B. A., et al. (2006). Understanding the lunar surface and space-Moon interactions. Reviews in Mineralogy \& Geochemistry, 60, 83-219. https://doi.org/10.2138/rmg.2006.60.2

Kadono, T. (1999). Hypervelocity impact into low density material and cometary outburst. Planetary and Space Science, 47(3), 305-318. https://doi.org/10.1016/S0032-0633(98)00039-7

McKay, D. S., Heiken, G., Basu, A., Blanford, G., Simon, S., Reedy, R., et al. (1991). The lunar regolith. In G. H. Heiken, D. T. Vaniman, \& B. M. French (Eds.), Lunar sourcebook (pp. 285 - 356). Cambridge: Cambridge University Press. 
Michael, G. G. \& Neukum, G. (2010). Planetary surface dating from crater size-frequency distribution measurements: Partial resurfacing events and statistical age uncertainty. Earth and Planetary Science Letters, 294(3-4), 223-229. https://doi.org/10.1016/j.epsl.2009.12.041

Michael, G. G., Kneissl, T., \& Neesemann, A. (2016). Planetary surface dating from crater sizefrequency distribution measurements: Poisson timing analysis. Icarus, 277, 279-285. https://dx.doi.org/10.1016/j.icarus.2016.05.019

Neish, C. D., Hamilton, C. W., Hughes, S. S., Nawotniak, S. K., Garry, W. B., Skok, J. R., et al. (2017). Terrestrial analogues for lunar impact melt flows. Icarus, 281, 73-89. https://doi.org/10.1016/j.icarus.2016.08.008

Neukum, G., Ivanov, B. A., \& Hartmann, W. K. (2001). Cratering records in the inner solar system in relation to the lunar reference system. Space Science Reviews, 96(1-4), 55-86.

Ohtake, M., Haruyama, J., Matsunaga, T., Yokota, Y., Morota, T., Honda, C., \& LISM team (2008). Performance and scientific objectives of the SELENE (KAGUYA) Multiband Imager, Earth Planets Space, 60, 257-264. https://doi.org/10.1186/BF03352789

Okamoto, T., \& Nakamura, A. M. (2017). Scaling of impact-generated cavity-size for highly porous targets and its application to cometary surfaces. Icarus, 292, 234-244. https://doi.org/10.1016/j.icarus.2017.01.007

Parfitt, E. A., \& Wilson, L. (1995). Explosive volcanic eruptions-IX. The transition between Hawaiian-style lava fountaining and Strombolian explosive activity. Geophysical Journal International, 121(1), 226-232. https://doi.org/10.1111/j.1365-246X.1995.tb03523.x

Peck, D. L., Wright, T. L., \& Decker, R. W. (1979). The lava lakes of Kilauea. Scientific American, 241(4), 114-129. https://www.scientificamerican.com/article/the-lava-lakes-of-kilauea/

Qiao, L., Xiao, Z., Zhao, J., \& Xiao, L. (2016). Subsurface structures at the Chang'e-3 landing site: Interpretations from orbital and in-situ imagery data. Journal of Earth Science, 27(4), 707-715. http://dx.doi.org/10.1007/s12583-015-0655-3

Qiao, L., Head, J., Wilson, L., Xiao, L., Kreslavsky, M., \& Dufek, J. (2017). Ina pit crater on the Moon: Extrusion of waning-stage lava lake magmatic foam results in extremely young crater retention ages. Geology, 45(5), 455-458. https://doi.org/10.1130/G38594.1

Qiao, L., Head, J. W., Xiao, L., Wilson, L., \& Dufek, J. D. (2018). The role of substrate characteristics in producing anomalously young crater retention ages in volcanic deposits on the Moon: Morphology, topography, sub-resolution roughness and mode of emplacement of the Sosigenes Lunar Irregular Mare Patch (IMP). Meteoritics \& Planetary Science, 53(4), 778812. https://doi.org/10.1111/maps.13003.

Qiao, L., Head, J. W., Ling, Z., Wilson, L., Xiao, L., Dufek, J. D., \& Yan, J. (2019a). Geological characterization of the Ina shield volcano summit pit crater on the Moon: Evidence for extrusion of waning-stage lava lake magmatic foams and anomalously young crater retention ages. Journal of Geophysical Research: Planets, 124(4), 1100-1140. https://doi.org/10.1029/2018JE005841

Qiao, L., Head, J. W., Ling, Z., \& Wilson, L. (2019b). Exploring a sub-classification scheme for Irregular Mare Patches (IMPs), 50th Lunar and Planetary Science Conference, Lunar and Planetary Institute, The Woodlands, Texas, abstract \#2358.

Quaide, W. L., \& Oberbeck, V. R. (1968). Thickness determinations of the lunar surface layer from lunar impact craters. Journal of Geophysical Research, 73(16), 5247-5270. http://dx.doi.org/10.1029/JB073i016p05247

Ripepe, M., Donne, D. D., Harris, A., Marchetti, E., \& Ulivieri, G. (2008). Dynamics of strombolian activity, In S. Calvari, S. Inguaggiato, G. Puglisi, M. Ripepe, \& M. Rosi (Eds.), 
The stromboli volcano: An integrated study of the 2002-2003 eruption, AGU Geophysical Monograph Series (Vol. 182, pp. 39-48). Washington, DC: American Geophysical Union. https://doi.org/10.1029/182GM05

Robinson, M. S., Brylow, S. M., Tschimmel, M., Humm, D., Lawrence, S. J., Thomas, P. C., et al. (2010). Lunar Reconnaissance Orbiter Camera (LROC) instrument overview. Space Science Reviews, 150(1), 81-124. https://doi.org/10.1007/s11214-010-9634-2

Robinson, M. S., Ashley, J. W., Boyd, A. K., Wagner, R. V., Speyerer, E. J., Ray Hawke, B., et al. (2012). Confirmation of sublunarean voids and thin layering in mare deposits. Planetary and Space Science, 69(1), 18-27. https://doi.org/10.1016/j.pss.2012.05.008

Rutherford, M. J., Head, J. W., Saal, A. E., Hauri, E., \& Wilson, L. (2017). Model for the origin, ascent, and eruption of lunar picritic magmas. American Mineralogist, 102(10), 2045-2053. https://dx.doi.org/10.2138/am-2017-5994ccbyncnd

Schultz, P. H., Staid, M. I., \& Pieters, C. M. (2006). Lunar activity from recent gas release. Nature, 444(7116), 184-186. https://doi.org/10.1038/nature05303

Staid, M. I., \& Pieters, C. M. (2000). Integrated spectral analysis of mare soils and craters: Applications to eastern nearside basalts. Icarus, 145(1), 122-139. https://doi.org/10.1006/icar.1999.6319

Staid, M., Isaacson, P., Petro, N., Boardman, J., Pieters, C. M., Head, J. W., et al. (2011). The spectral properties of Ina: New observations from the Moon Mineralogy Mapper. 42nd Lunar and Planetary Science Conference, Lunar and Planetary Institute, The Woodlands, Texas, abstract \#2499.

Stooke, P. J. (2012). Lunar meniscus hollows. 43rd Lunar and Planetary Science Conference, Lunar and Planetary Institute, The Woodlands, Texas, abstract \#1011.

Stopar, J. D., Robinson, M. S., van der Bogert, C. H., Hiesinger, H., Ostrach, L. R., Giguere, T. A., \& Lawrence, S. J. (2017). Young lunar volcanism: Irregular mare patches as drained lava ponds and inflated flows. 48th Lunar and Planetary Science Conference, Lunar and Planetary Institute, The Woodlands, Texas, abstract \#1792.

Strain, P. L., \& El-Baz, F. (1980). The geology and morphology of Ina. In Proceedings of the 11th Lunar Science Conference (pp. 2437-2446).

Taylor, S. R. (1989). Growth of planetary crusts. Tectonophysics, 161(3), 147-156. https://doi.org/10.1016/0040-1951(89)90151-0

Tilling, R. I. (1987). Fluctuations in surface height of active lava lakes during 1972-1974 Mauna Ulu Eruption, Kilauea Volcano, Hawaii. Journal of Geophysical Research: Solid Earth, 92(B13), 13721-13730. https://doi.org/10.1029/JB092iB13p13721

Tilling, R. I., Christiansen, R. I., Duffield, W. A., Endo, E. T., Holcomb, R. T., Koyanagi, R. Y. , Peterson, D. W., \& Unger, J. D. (1987). The 1972-1974 Mauna Ulu eruption, Kilauea volcano: An example of quasi-steady-state magma transfer, In R. W. Decker, T. L. Wright, \& P. H. Stauffer (Eds.), Volcanism in Hawaii, U.S. Geological Survey Professional Paper 1350 (pp. 405-469). Washington: United States Government Printing Office.

Trask, N. J. (1966). Size and spatial distribution of craters estimated from the Ranger photographs, In Ranger VIII and IX, Part II, Experimenters' Analyses and Interpretations (JPL Technical Reports 32-800, pp. 252-264). Pasadena, CA: Jet Propulsion Lab.

Tye, A. R., \& Head, J. W. (2013). Mare Tranquillitatis: Distribution of mare domes, relation to broad mare rise, and evidence of a previously unrecognized basin from LOLA altimetric data. 44th Lunar and Planetary Science Conference, Lunar and Planetary Institute, The Woodlands, Texas, abstract \#1319. 
Valantinas, A., Kinch, K. M., \& Bridžius, A. (2018). Low crater frequencies and low model ages in lunar maria: Recent endogenic activity or degradation effects? Meteoritics \& Planetary Science, 53(4), 826-838. https://doi.org/10.1111/maps.13033

Whitaker, E. A. (1972). An unusual mare feature, In Apollo 15 Preliminary Science Report (NASA SP-289, pp. 25-84-25-85).

Wilcox, B. B., Robinson, M. S., Thomas, P. C., \& Hawke, B. R. (2005). Constraints on the depth and variability of the lunar regolith. Meteoritics \& Planetary Science, 40(5), 695-710. https://doi.org/10.1111/j.1945-5100.2005.tb00974.x

Wieczorek, M. A., Jolliff, B. L., Khan, A., Pritchard, M. E., Weiss, B. P., Williams, J. G., et al. (2006). The constitution and structure of the lunar interior. Reviews in Mineralogy and Geochemistry, 60(1), 221-364. https://doi.org/10.2138/rmg.2006.60.3

Wilson, L., \& Head, J. W. (1981). Ascent and eruption of basaltic magma on the Earth and Moon. Journal of Geophysical Research: Solid Earth, 86(B4), 2971-3001. https://doi.org/10.1029/JB086iB04p02971

Wilson, L., \& Head, J. W. (2003). Deep generation of magmatic gas on the Moon and implications for pyroclastic eruptions. Geophysical Research Letters, 30(12). https://doi.org/10.1029/2002GL016082

Wilson, L., \& Head, J. W. (2017a). Eruption of magmatic foams on the Moon: Formation in the waning stages of dike emplacement events as an explanation of "irregular mare patches". Journal of Volcanology and Geothermal Research, 335, 113-127, https://doi.org/10.1016/j.jvolgeores.2017.02.009.

Wilson, L., \& Head, J. W. (2017b). Generation, ascent and eruption of magma on the Moon: New insights into source depths, magma supply, intrusions and effusive/explosive eruptions (Part 1: Theory). Icarus, 283, 146-175, https://doi.org/10.1016/j.icarus.2015.12.039.

Wilson, L., \& Head, J. W. (2018). Controls on lunar basaltic volcanic eruption structure and morphology: Gas release patterns in sequential eruption phases. Geophysical Research Letters, 45, 5852-5859. https://doi.org/10.1029/2018GL078327

Wilson, L., Head, J. W., \& Zhang, F. (2019). A theoretical model for the formation of Ring Moat Dome Structures: Products of second boiling in lunar basaltic lava flows. Journal of Volcanology and Geothermal Research, 374, 160-180.

https://doi.org/10.1016/j.jvolgeores.2019.02.018

Wöhler, C., Lena, R., Lazzarotti, P., Phillips, J., Wirths, M., \& Pujic, Z. (2006). A combined spectrophotometric and morphometric study of the lunar mare dome fields near Cauchy, Arago, Hortensius, and Milichius. Icarus, 183(2), 237-264. https://doi.org/10.1016/j.icarus.2006.03.003

Wöhler, C., Lena, R., \& Phillips, J. (2007). Formation of lunar mare domes along crustal fractures: Rheologic conditions, dimensions of feeder dikes, and the role of magma evolution. Icarus, 189(2), 279-307. https://doi.org/10.1016/j.icarus.2007.01.011

Wolfe, E. W., Garcia, M. O., Jackson, D. B., Koyanagi, R. Y., Neal, C. A., \& Okamura, A. T. (1987), The Puu Oo eruption of Kilauea Volcano, Episodes 1-20, January 3, 1983, to June 8, 1984, In R. W. Decker, T. L. Wright, \& P. H. Stauffer (Eds.), Volcanism in Hawaii, U.S. Geological Survey Professional Paper 1350 (pp. 471-508). Washington: United States Government Printing Office.

Yasui, M., Matsumoto, E., \& Arakawa, M. (2015). Experimental study on impact-induced seismic wave propagation through granular materials. Icarus, 260, 320-331. https://doi.org/10.1016/j.icarus.2015.07.032

Zhang, F., Zhu, M. H., Bugiolacchi, R., Huang, Q., Osinski, G. R., Xiao, L., \& Zou, Y. L. (2018). Diversity of basaltic lunar volcanism associated with buried impact structures: 
1040 Implications for intrusive and extrusive events. Icarus, 307, 216-234.

1041 https://doi.org/10.1016/j.icarus.2017.10.039 


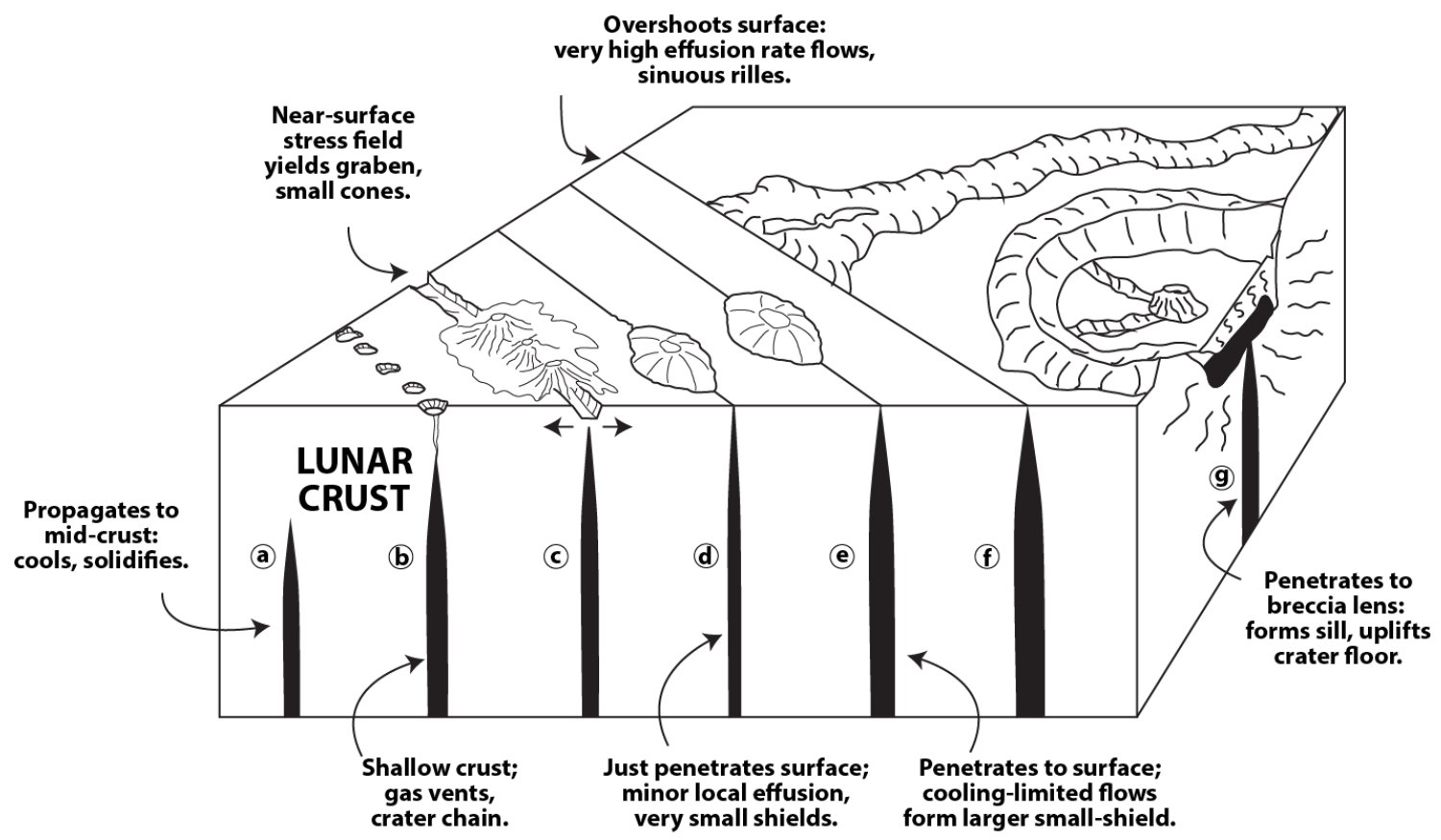

1044 Figure 1. Synthesis block diagram of mare basalt dikes approaching, intruding, stalling and erupting on the Moon. Small shield volcanoes $(d, e)$ represent relatively small-volume, low magma rise rate eruptions compared with much larger dikes (f) that form high-volume, high effusion rate eruptions. The Cauchy 5 small shield (5-6 km diameter) lies at the small end of the eruption volume (d) compared to the larger (e), $25 \mathrm{~km}$ diameter, Ina small shield volcano (Figure 4). 
Confidential manuscript submitted to Journal of Geophysical Research: Planets

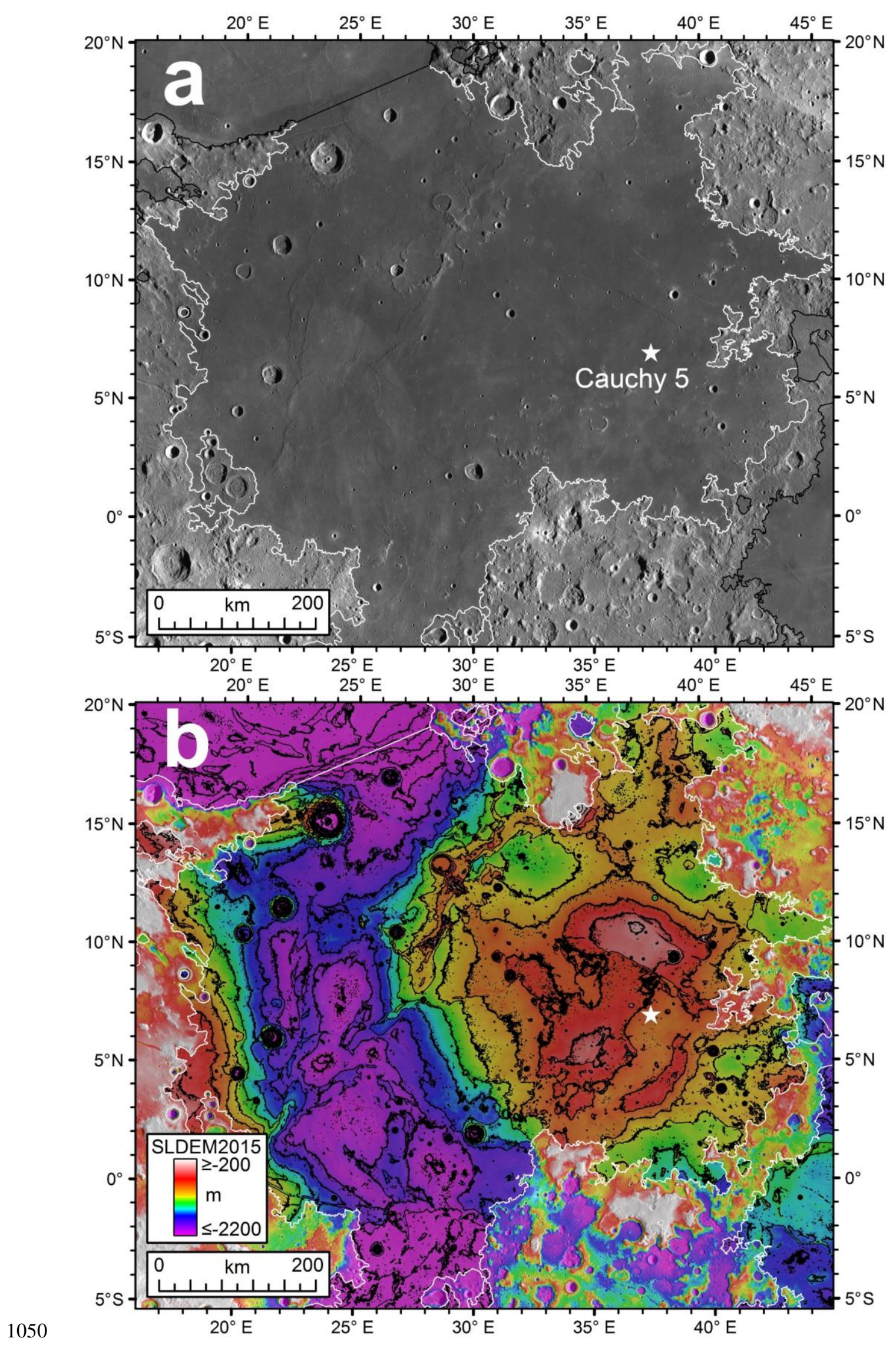


Figure 2. Geologic setting of the Cauchy 5 small shield volcano in Mare Tranquillitatis: (a) LROC WAC (Robinson et al., 2010) low-sun mosaic, the boundary of Mare Tranquillitatis are delineated by white outlines, other maria by black outlines and the location of Cauchy 5 small shield is indicated by the white star, (b) SLDEM2015 (SELENE-TC+LRO-LOLA merged DEM, Barker et al., 2016)) topography, with $200 \mathrm{~m}$-interval contour overlain (only for mare regions outlined by white polygons). The projection is lambert conformal conic projection, with central meridian of $30^{\circ} \mathrm{E}$ and standard parallels of $2^{\circ} \mathrm{N}$ and $16^{\circ} \mathrm{N}$, and north is up.
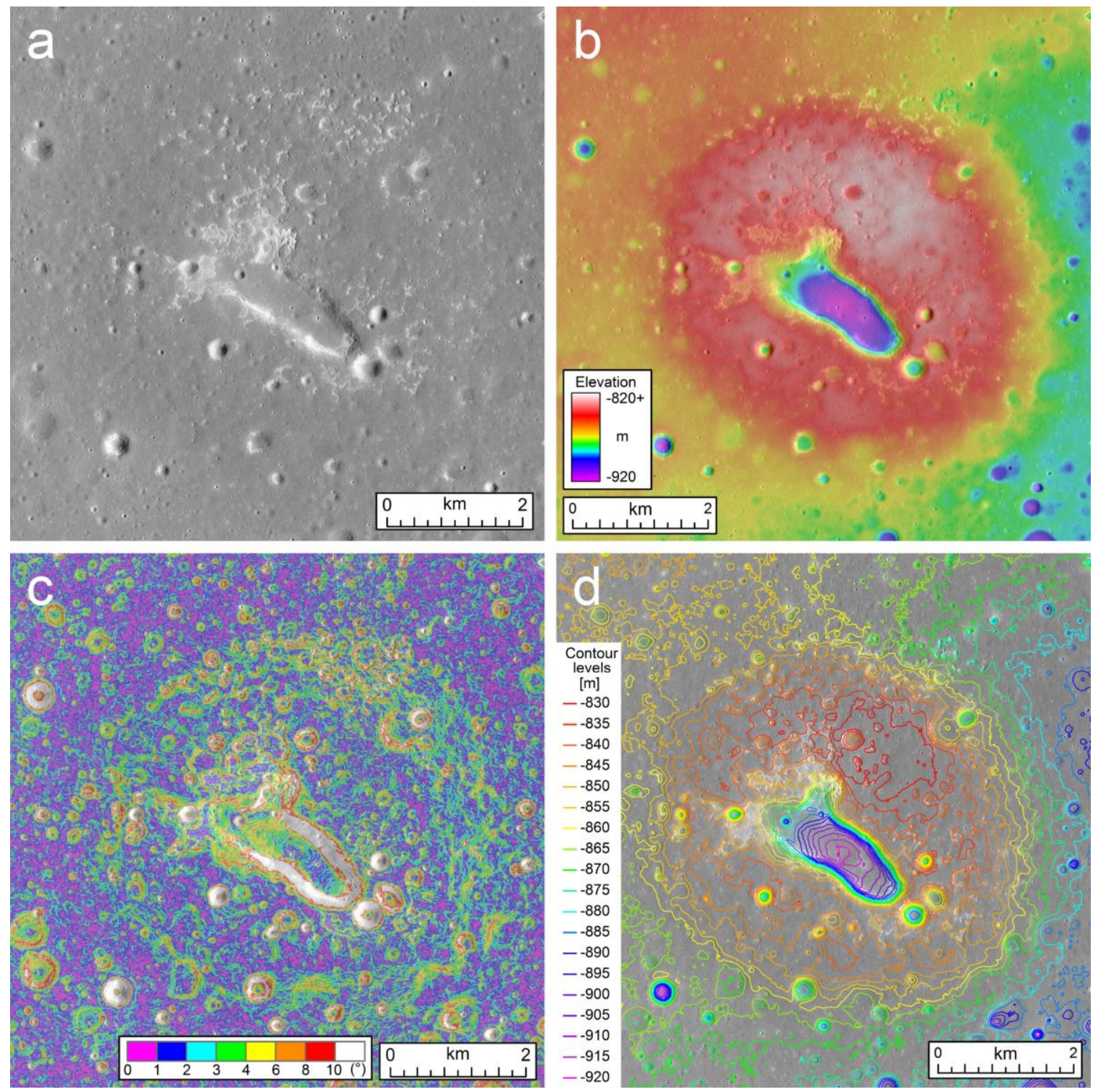

Figure 3. Cauchy 5 small shield volcano mapped by LROC NAC: (a) LROC NAC image (frame M1108025067, 1.2 m/pixel), (b) LROC NAC DTM topography (5 m/pixel; Robinson et al., 2010; Henriksen et al., 2017), (c) NAC DTM-derived slope map (15 m baseline) and (d) $5 \mathrm{~m}$ contour interval map. All the images of the Cauchy 5 feature in this work are in a sinusoidal projection centered at $37.592^{\circ} \mathrm{E}$, and north is up. 

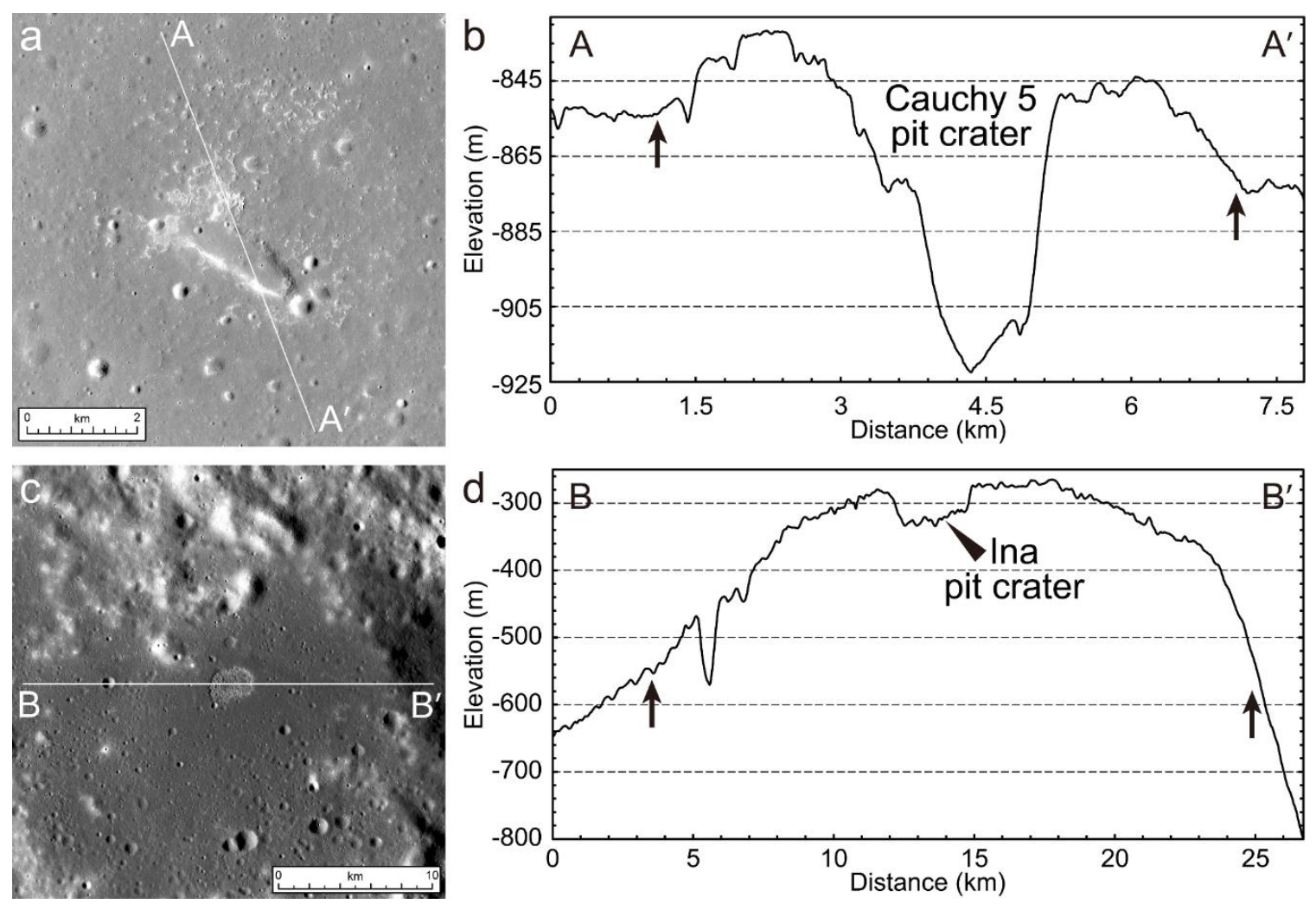

Figure 4. LROC NAC DTM topographic profiles (5 m spatial sampling size) across the Cauchy 5 small shield volcano (panels a, b) and its comparison with the much larger Ina shield volcano

1067 (2 m spatial sampling size; panels c, d). The arrows in panels (b) and (d) mark the location of the 1068 base of the shields, and the locations of the Cauchy and Ina summit pit craters are labeled. Panel 1069 (c) is a sinusoidal projection centered at $5.3473^{\circ} \mathrm{E}$, and north is up. 

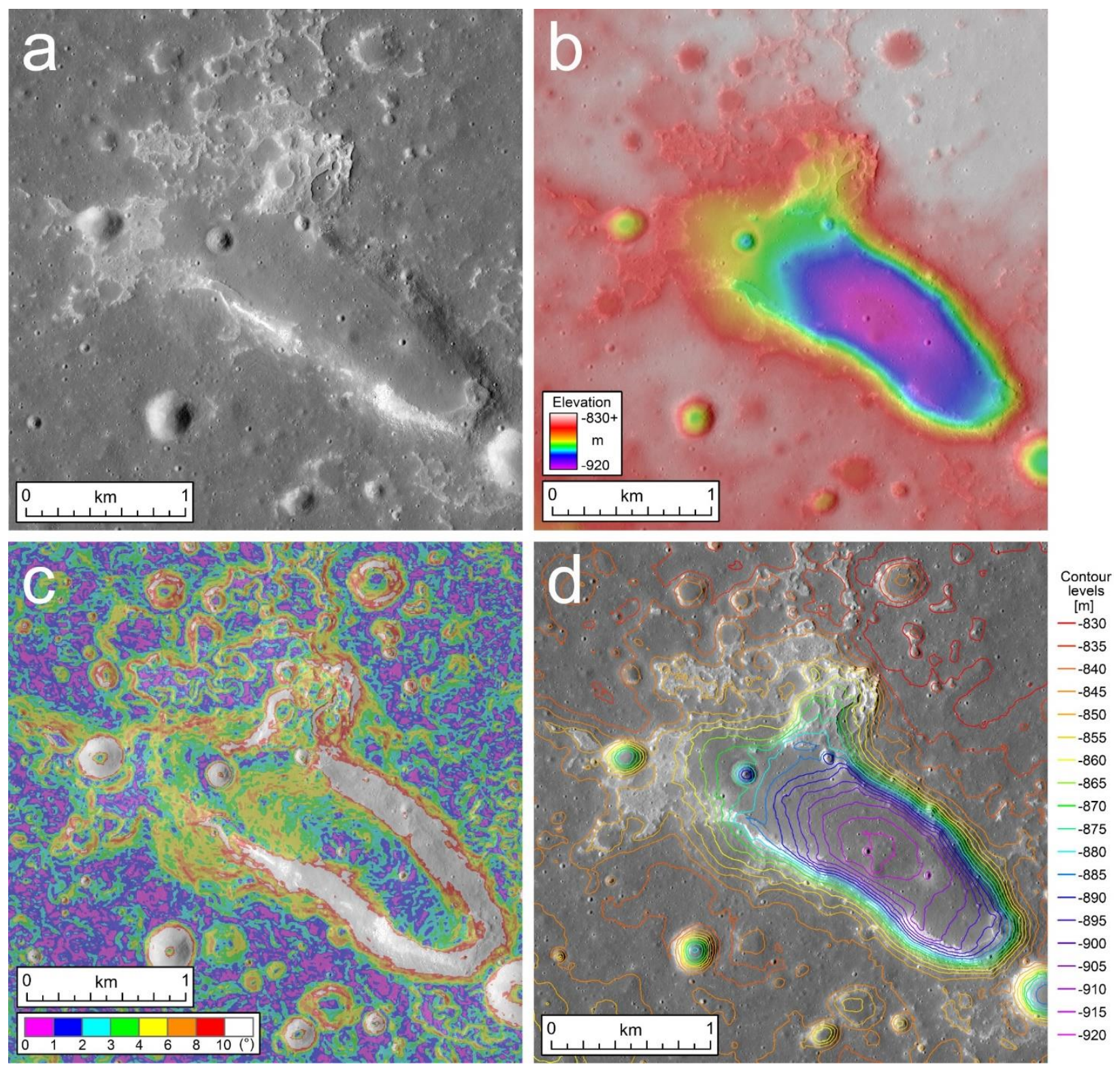

1071 Figure 5. Cauchy 5 small shield volcano summit pit crater: (a) LROC NAC frame

1072 M1108025067, $1.2 \mathrm{~m} / \mathrm{pixel,} \mathrm{(b)} \mathrm{LROC} \mathrm{NAC} \mathrm{DTM} \mathrm{topography} \mathrm{overlain} \mathrm{on} \mathrm{NAC} \mathrm{M1108025067,}$ 1073 (c) NAC DTM-derived slope map and (d) $5 \mathrm{~m}$ contour interval overlaid on NAC image. 

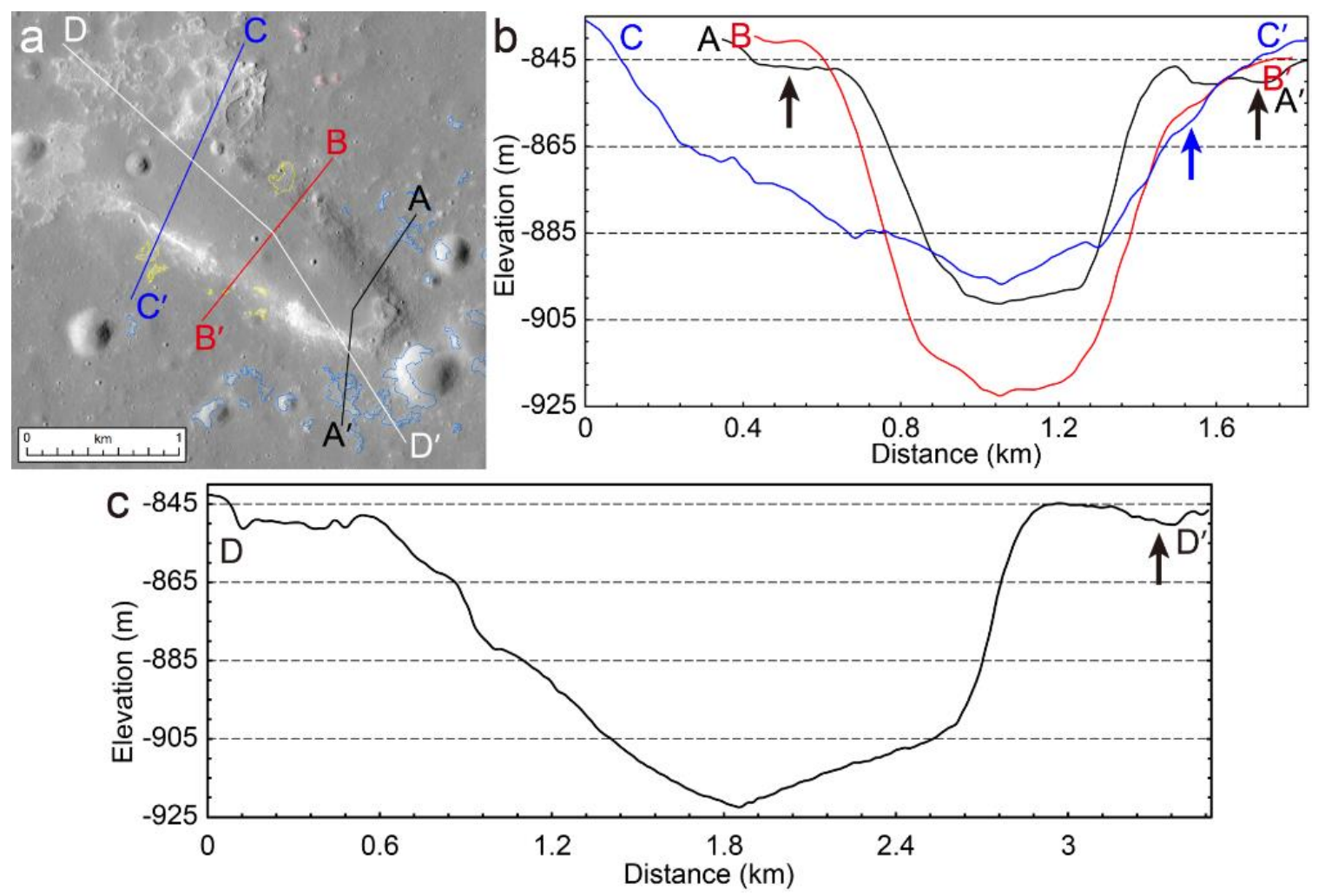

1074

1075

1076

1077

1078

1079

1080

1081

Figure 6. LROC NAC DTM topographic profiles (b) across and (c) along the Cauchy 5 eruptive vent; the locations of these profiles are shown in panel (a), LROC NAC image M1108025067. Color polygons in panel (a) are mapped small mare IMP-like pits in different locations: pink: northern flank; blue: southeastern rim; yellow: other regions (see Figure 8a for the complete mapping result). Arrows in the topographic profiles show the location of small IMP-like pits: black arrows for pits on the path of profile AA' and blue arrows for pits on the path of profile CC'. 

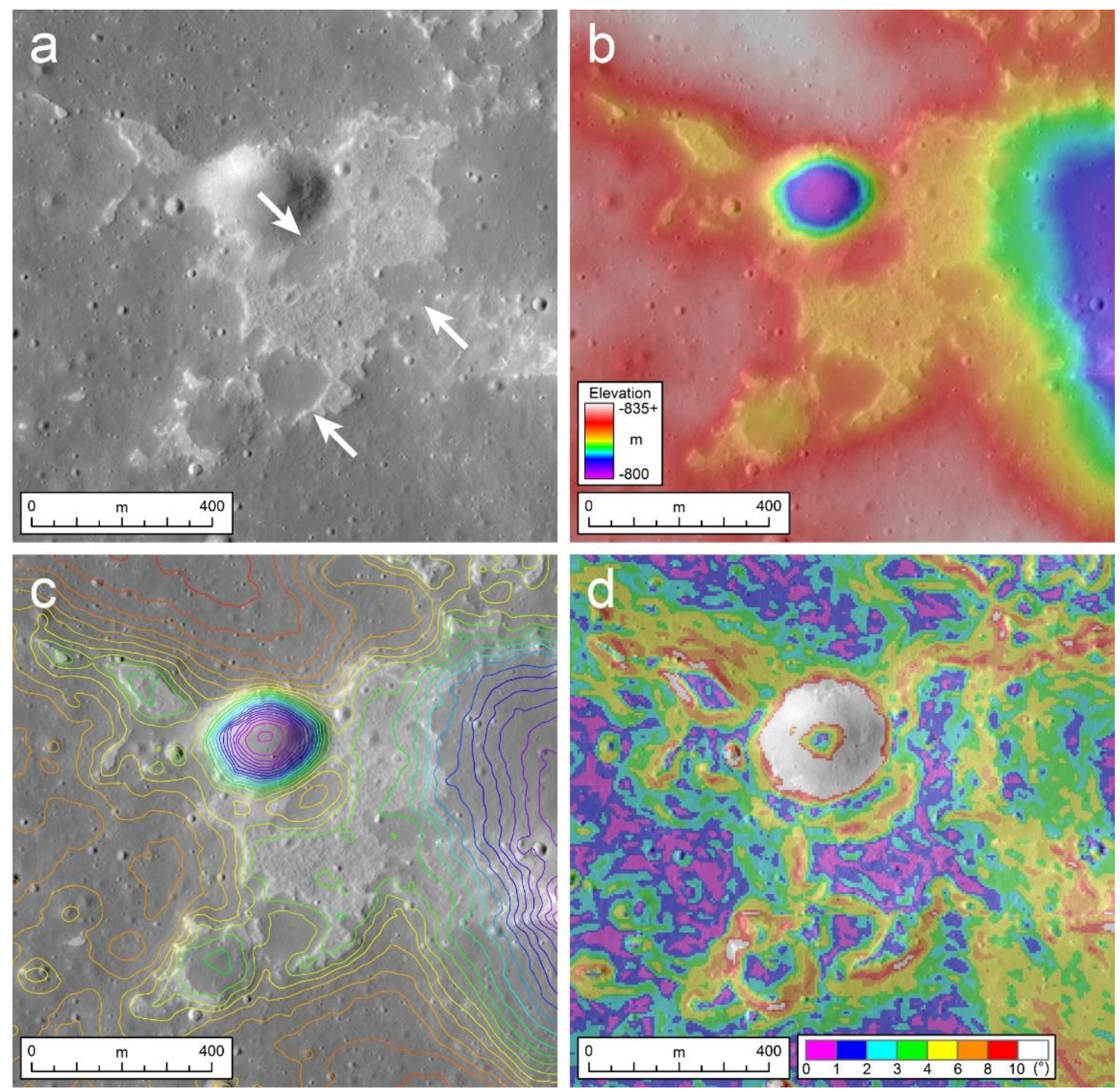

1083

Figure 7. Image and topographic maps of the NW rim of Cauchy 5 shield volcano. (a) LROC

1084 NAC image M1108025067, (b) NAC DTM topography, (c) 2 m contour interval (magenta and purple contours for lower elevations and red and yellow for higher elevations) and (d) NAC DTM slope overlaid on LROC NAC image. The white arrows in panel (a) indicate the mound terrains occurring on the NW rim, which is surrounded by bright and rough terrains. 

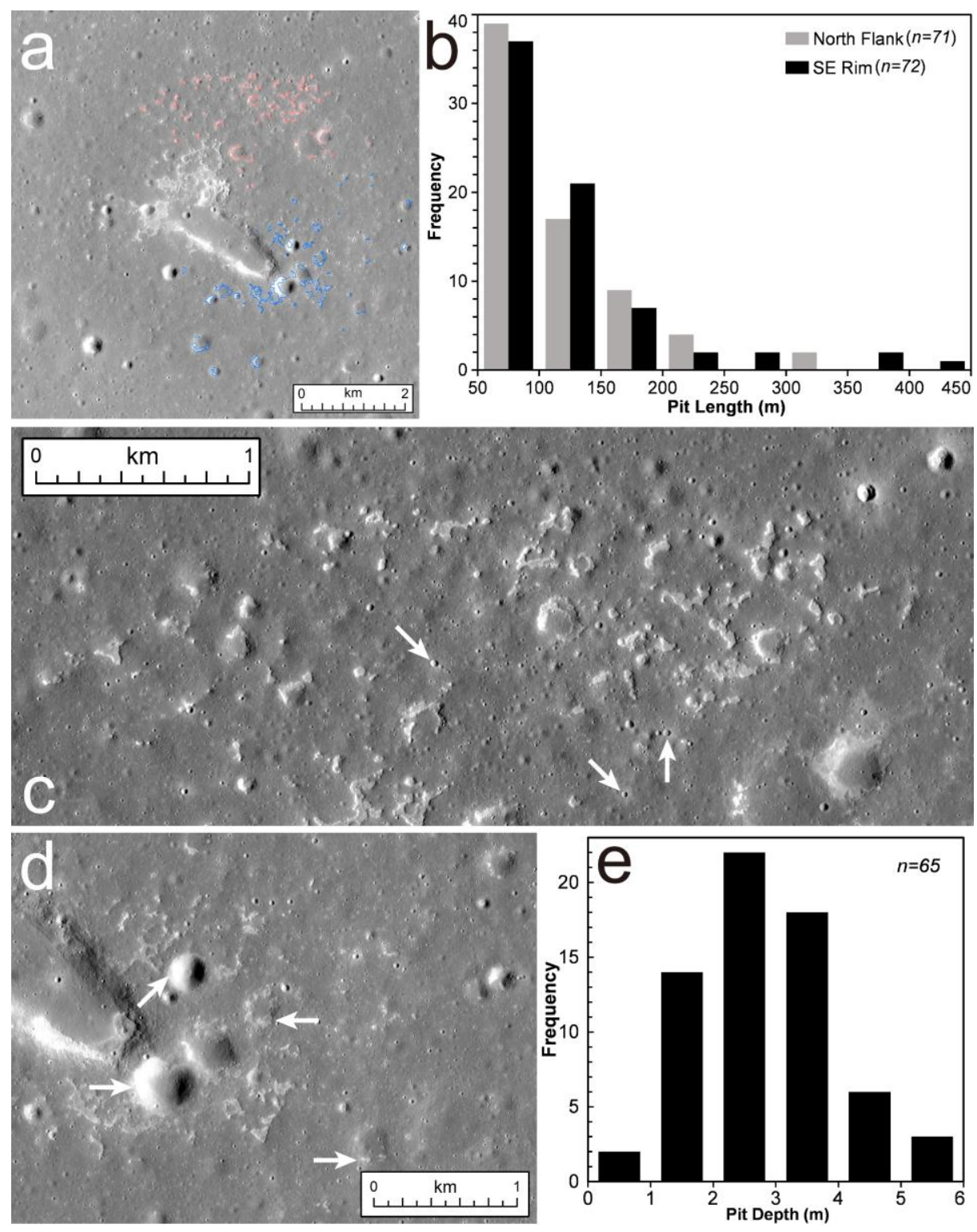

1089

Figure 8. Volcano flank pit craters: (a) Spatial distribution (base map is a portion of LROC NAC M1108025067), (b) length-frequency distributions of the abundant small pit-type IMPs $\geq 50 \mathrm{~m}$ in length mapped in the north shield flank (pink polygons) and southeast rim (blue polygons) and (e) depth-frequency distribution of all pits $\geq 50 \mathrm{~m}$ in length on relatively flat surfaces $(n=65)$. (c) Detailed image of the northern shield flank pit-type IMP occurrences, LROC NAC frame M1108025067. The white arrows indicate examples of post-foam overflow impact craters, interpreted to have penetrated the surface of the foamy flow layer and exposed the underlying shield/mare basaltic deposits, generating blocky crater interiors. (d) LROC NAC image (M1108025067) of the southeast crater rim pit-type IMP occurrences. The white arrows mark several relatively extensive IMP-like pits on the interior walls of some depressions (also noted in Figure 9). 

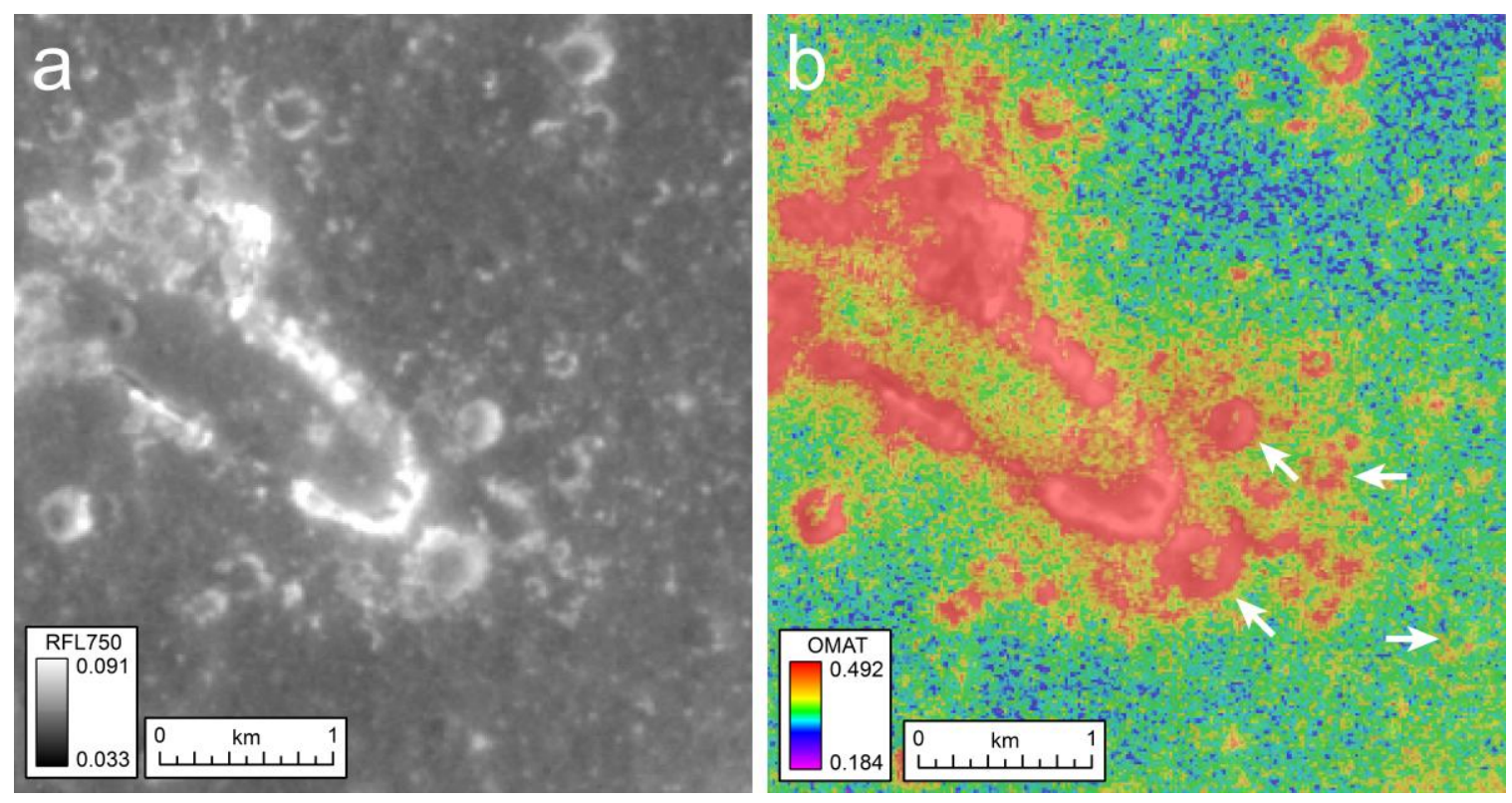

1101 Figure 9. Kaguya MI (a) $750 \mathrm{~nm}$ reflectance (RFL750) and (b) optical maturity (OMAT) maps 1102 (Ohtake et al., 2008; Lemelin et al., 2015) of the Cauchy 5 pit crater and southeastern rim. The 1103 arrows in panel (b) mark the relatively extensive mapped pits in Figure 8a and pointed out in 1104 Figure 8d. 

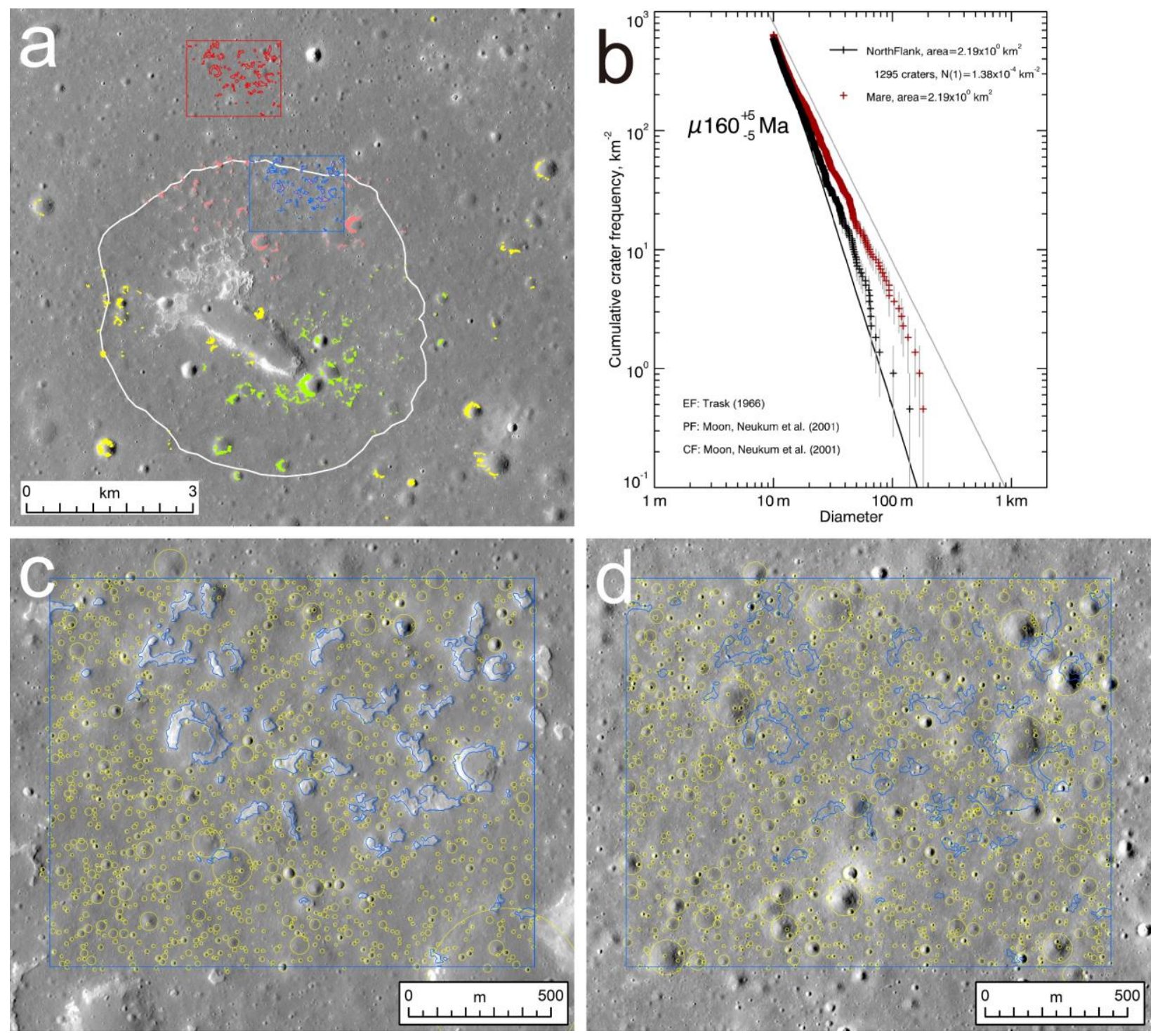

Figure 10. (a) Locations of the Cauchy 5 crater population analysis working areas. Blue polygons: crater counting area on the shield flank outflows (pitted areas mapped in Figure 8a are not included), red polygons: crater counting area on the surrounding mare, with same shape as the shield flank flow counting area. The white line is the approximate location of the base of the shield. Pink patches are the mapped IMP-like pits on the north flank, green patches are pits on the southeast rim and yellow patches are small pits elsewhere. (b) Cumulative size-frequency distribution plots of impact craters (diameter $\geq 10 \mathrm{~m}$ ) superposed on the north shield flank interpit surface (black crosses) and surrounding mare (red crosses). The gray line on the right is the lunar equilibrium function (EF) curve from Trask (1966). Model ages are fitted on the basis of the production function (PF) and chronology function (CF) proposed by Neukum et al. (2001), using the CraterStats software package (Micheal \& Neukum, 2010; Michael et al. 2016): on the north shield flank, fitting craters $\geq 10 \mathrm{~m}$ in diameter gives a model age of $160 \mathrm{Ma}$; the crater diameter fit ranges are indicated by the horizontal extent of the fitted isochrons; the $\mu$ before the calculated model ages is the function representing the uncertainty of calibration of the chronology model (Michael et al. 2016). (c) Crater count map of the north shield flank inter-pit 
1121 surface. (d) Spatial distribution of the counted impact craters on the surrounding mare.

1122 Background images of panels a, $\mathrm{c}$ and d are all cropped from LROC NAC frame 1138873574.

\begin{tabular}{|c|c|c|c|c|}
\hline & PHASE 1 & PHASE 2 & PHASE 3 & PHASE 4 \\
\hline $\begin{array}{l}\text { Eruption } \\
\text { Phase }\end{array}$ & $\begin{array}{c}\text { Dike } \\
\text { penetrates } \\
\text { to surface, } \\
\text { transient gas } \\
\text { release } \\
\text { phase }\end{array}$ & $\begin{array}{c}\text { Dike base } \\
\text { still rising, } \\
\text { high flux } \\
\text { hawaiian } \\
\text { eruptive } \\
\text { phase }\end{array}$ & $\begin{array}{c}\text { Dike } \\
\text { equilibration, } \\
\text { lower flux } \\
\text { hawaiian to } \\
\text { strombolian } \\
\text { transition } \\
\text { phase }\end{array}$ & $\begin{array}{l}\text { Dike closing, } \\
\text { strombolian } \\
\text { vesicular } \\
\text { flow phase }\end{array}$ \\
\hline \multirow{2}{*}{$\begin{array}{c}\text { Dike } \\
\text { Configuration }\end{array}$} & Crust & & & \\
\hline & Mantle & & & $\sqrt{ }$ \\
\hline \multirow{3}{*}{$\begin{array}{l}\text { Surface } \\
\text { Eruption } \\
\text { Style }\end{array}$} & \multirow[t]{2}{*}{$\begin{array}{c}\text { Transparent } \\
\text { gas }\end{array}$} & $\begin{array}{l}\text { Opaque pyroclastic } \\
\text { fountain } \\
\frac{\text { Sinuous }}{\text { silleus }}\end{array}$ & \multirow{2}{*}{$\begin{array}{c}\text { Fountain } \\
\text { declines } \\
\text { toward } \\
\text { strombolian }\end{array}$} & $\begin{array}{l}\text { a) Proximal } \\
\text { foam flow }\end{array}$ \\
\hline & & & & $\begin{array}{l}\text { b) Distal flow } \\
\text { inflation }\end{array}$ \\
\hline & & $\begin{array}{l}\text { Lava } \\
\text { lake }\end{array}$ & 70 & (7) \\
\hline $\begin{array}{l}\text { Magma Rise } \\
\text { Speed }\end{array}$ & 30 to $20 \mathrm{~m} / \mathrm{s}$ & 20 to $10 \mathrm{~m} / \mathrm{s}$ & 5 to $<1 \mathrm{~m} / \mathrm{s}$ & $<1 \mathrm{~m} / \mathrm{s}$ \\
\hline $\begin{array}{c}\text { Magma } \\
\text { Volume Flux }\end{array}$ & $\sim 10^{6} \mathrm{~m}^{3} / \mathrm{s}$ & $10^{6}$ to $10^{5} \mathrm{~m}^{3} / \mathrm{s}$ & $10^{5}$ to $\sim 10^{4} \mathrm{~m}^{3} / \mathrm{s}$ & $\sim 10^{4} \mathrm{~m}^{3} / \mathrm{s}$ \\
\hline $\begin{array}{c}\text { Percent Dike } \\
\text { Volume } \\
\text { Erupted }\end{array}$ & $<5 \%$ & $\sim 30 \%$ & $\sim 30 \%$ & $\sim 35 \%$ \\
\hline $\begin{array}{c}\text { Phase } \\
\text { Duration }\end{array}$ & $\sim 3$ minutes & $5-10$ days & 2-3 days & $10-100$ days \\
\hline $\begin{array}{c}\text { Flow } \\
\text { Advance } \\
\text { Rate }\end{array}$ & $n / a$ & $\sim 3$ to $0.1 \mathrm{~m} / \mathrm{s}$ & $0.03 \mathrm{~m} / \mathrm{s}$ & $0.01 \mathrm{~m} / \mathrm{s}$ \\
\hline $\begin{array}{c}\text { Flow } \\
\text { Advance } \\
\text { Distance }\end{array}$ & $n / a$ & $300 \mathrm{~km}$ & $305 \mathrm{~km}$ & $335 \mathrm{~km}$ \\
\hline $\begin{array}{l}\text { Vesicularity } \\
\text { of Flow }\end{array}$ & $n / a$ & zero & $\begin{array}{c}\text { low, but } \\
\text { increasing }\end{array}$ & very high \\
\hline
\end{tabular}

\begin{tabular}{|c|c|c|c|c|}
\hline \multirow[b]{2}{*}{$\begin{array}{c}\text { B } \\
\text { Eruption } \\
\text { Phase }\end{array}$} & PHASE 1 & PHASE 2 & PHASE 3 & PHASE 4 \\
\hline & $\begin{array}{c}\text { Dike } \\
\text { penetrates } \\
\text { to surface, } \\
\text { transient gas } \\
\text { release } \\
\text { phase }\end{array}$ & $\begin{array}{c}\text { Dike base } \\
\text { decelerates, } \\
\text { low flux } \\
\text { hawaiian } \\
\text { eruptive } \\
\text { phase }\end{array}$ & $\begin{array}{c}\text { Dike } \\
\text { equilibration, } \\
\text { low flux } \\
\text { hawaiian to } \\
\text { strombolian } \\
\text { transition } \\
\text { phase } \\
\end{array}$ & $\begin{array}{l}\text { Dike closing, } \\
\text { very low flux } \\
\text { strombolian } \\
\text { vesicular } \\
\text { flow phase }\end{array}$ \\
\hline \multirow{2}{*}{$\begin{array}{c}\text { Dike } \\
\text { Configuration }\end{array}$} & Crust & & l] & \\
\hline & Mantle & & V & V \\
\hline \multirow{3}{*}{$\begin{array}{l}\text { Surface } \\
\text { Eruption } \\
\text { Style }\end{array}$} & & & $\begin{array}{l}\text { Fountain } \\
\text { declines } \\
\text { toward }\end{array}$ & \multirow{3}{*}{$\begin{array}{l}\text { a) Initial flows } \\
\text { bulid shield } \\
\text { b) Final proximal } \\
\text { foam flows } \\
\text { oag }\end{array}$} \\
\hline & & & $\int 8$ & \\
\hline & & Lake & $7 \%$ & \\
\hline $\begin{array}{l}\text { Magma Rise } \\
\text { Speed }\end{array}$ & $\sim 10 \mathrm{~m} / \mathrm{s}$ & $\sim 1 \mathrm{~m} / \mathrm{s}$ & $\sim 0.1 \mathrm{~m} / \mathrm{s}$ & $<0.1 \mathrm{~m} / \mathrm{s}$ \\
\hline $\begin{array}{c}\text { Magma } \\
\text { Volume Flux }\end{array}$ & $\sim 10^{4} \mathrm{~m}^{3} / \mathrm{s}$ & $\sim 10^{3} \mathrm{~m}^{3} / \mathrm{s}$ & $\sim 300 \mathrm{~m}^{3} / \mathrm{s}$ & $\sim 100 \mathrm{~m}^{3} / \mathrm{s}$ \\
\hline $\begin{array}{l}\text { Percent Dike } \\
\text { Volume } \\
\text { Erupted }\end{array}$ & $\sim 0.1 \%$ & $\sim 0.05 \%$ & $\sim 0.1 \%$ & $\sim 0.25 \%$ \\
\hline $\begin{array}{l}\text { Phase } \\
\text { Duration }\end{array}$ & $\sim 3$ minutes & $\sim 1$ hour & $\sim 3$ days & $\sim 10$ days \\
\hline $\begin{array}{c}\text { Flow } \\
\text { Advance } \\
\text { Rate } \\
\end{array}$ & $n / a$ & $\sim 0.03 \mathrm{~m} / \mathrm{s}$ & $\sim 0.01 \mathrm{~m} / \mathrm{s}$ & $\sim 0.003 \mathrm{~m} / \mathrm{s}$ \\
\hline $\begin{array}{c}\text { Flow } \\
\text { Advance } \\
\text { Distance } \\
\end{array}$ & n/a & $\sim 100 \mathrm{~m}$ & $\sim 1 \mathrm{~km}$ & $\sim 2.5 \mathrm{~km}$ \\
\hline $\begin{array}{l}\text { Vesicularity } \\
\text { of Flow }\end{array}$ & $n / a$ & zero & high & very high \\
\hline
\end{tabular}

1124 Figure 11. The detailed nature of typical phases in mare basalt lava flow eruptions. a) The characteristics of the four eruption phases during a typical large-volume, high-effusion rate lunar lava flow eruption (Figure 1f), with diagrams and parameters representing average values (from Wilson and Head, 2018). The relative duration of individual phases depends on the total dike volume and vertical extent. b) In a low-volume, low effusion rate eruption typical of very small shield volcanoes such as Cauchy 5 (Figure 1d), Phases 2 and 3 are highly abbreviated, and Phase 11304 is relatively more significant. 

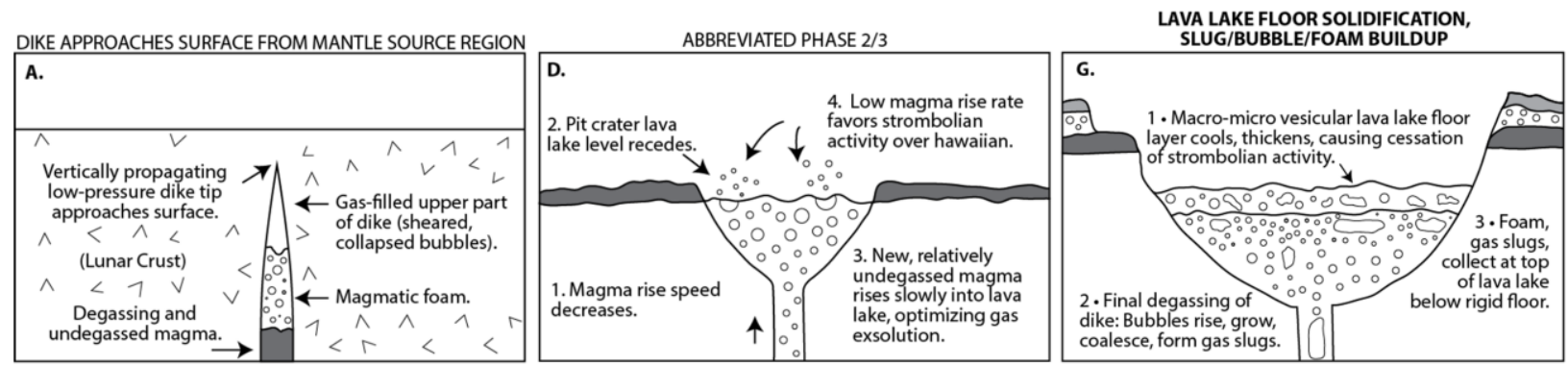

DIKE TIP PENETRATES TO SURFACE VACUUM,
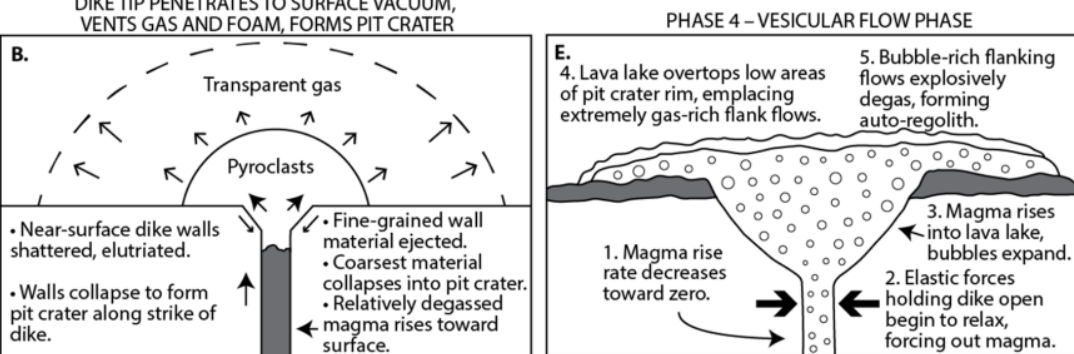

LAVA LAKE FLOOR CRACKING AND

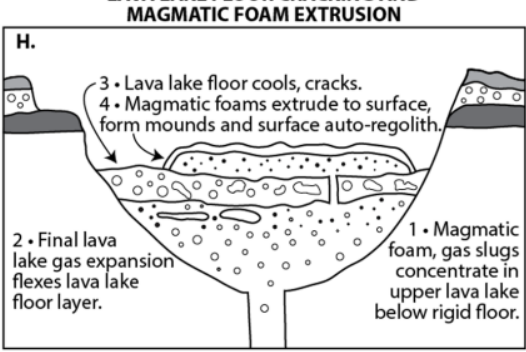

VOLATILE-DEPLETED MAGMAS FILL PIT CRATER AND OVERFLOW TO FORM SHIELD BASE
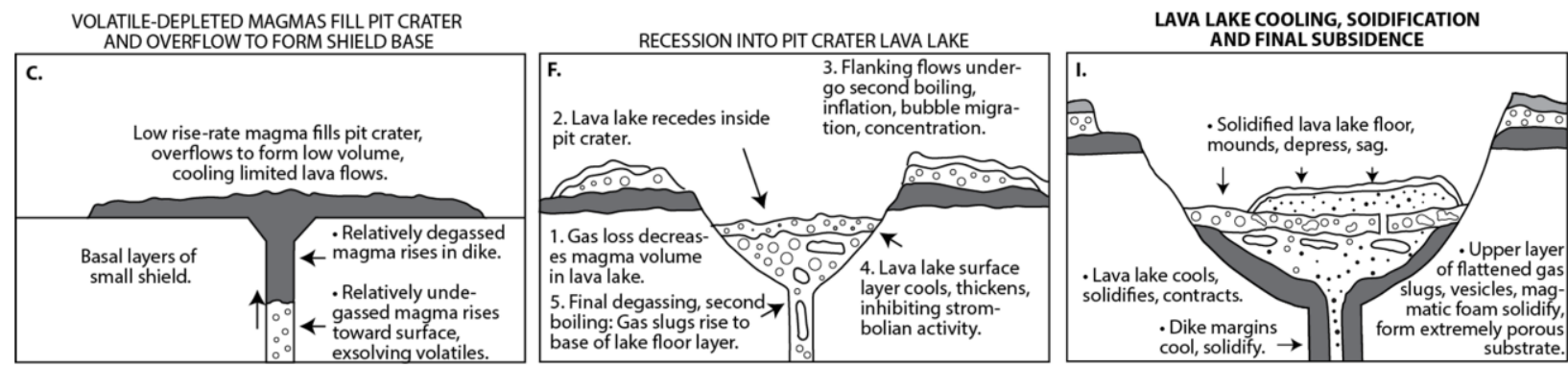

1132 Figure 12. The interpreted stages in the ascent, eruption, evolution and final cooling of the Cauchy 5 small shield volcano intrusive-extrusive event. (a) Dike approaches surface. (b) Dike tip penetrates to surface vacuum, explosively vents gas and foam, forms pit crater. (c) Low riserate, largely degassed magma below gas/foam in dike top rises to fill the newly formed pit crater, and overflows to form cooling limited basalt flows. (d) In the very abbreviated Phases 2 and 3 (relative to larger lava flows; Figure 11), the transition to Phase 4 activity occurs. (e) In Phase 4, the lava lake overflows, emplacing highly bubble-rich/vesicular lava flows on the shield flanks. (f) Lava recedes into the pit crater, forming a cooling and thickening lava lake surface layer. (g) As the lava lake floor layer thickens, strombolian activity is inhibited, and gas continues build-up below the floor as gas slugs, vesicles and foams. (h) As the lava lake cools, the floor layer cracks and magmatic foams in the upper lava lake extrude to form viscous-appearing mounds; the foam surface explosively decompresses, forming an auto-regolith layer. (i) Lava lake undergoes final

1144 cooling and subsidence. 

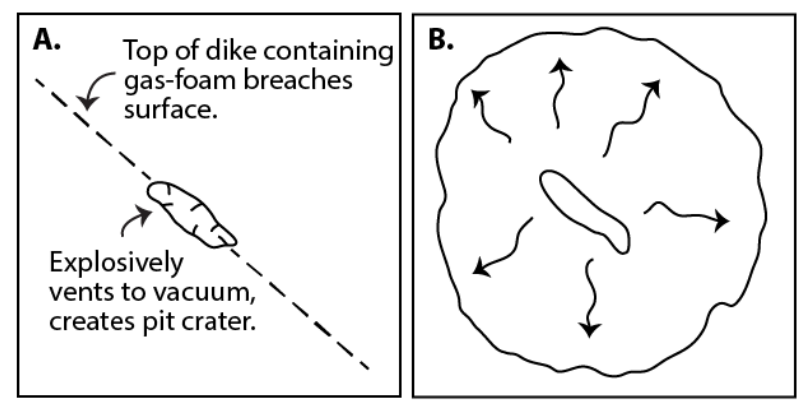

B. Degassed magma fills pit, overflows to form shield base.

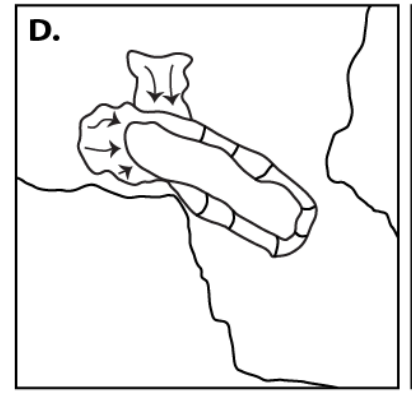

D. Continued gas loss causes drainback of proximal parts of bubble-rich/foamy flows into receding lava lake.

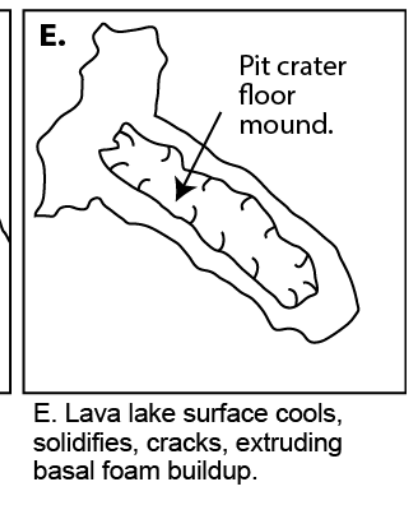

Figure 13. Map view of the stages in evolution of the Cauchy 5 small shield volcano. a) Upper part of dike penetrates to the surface, catastrophically vents gas and foam into the vacuum, causing collapse to form the elongate pit crater. b) Initial gas-depleted magma extrudes out of the pit crater to form initial stages of small shield. c) Second phase of shield building involves rise of gas-containing magma into the top of the dike and pit crater, significant degassing and bubble growth, coalescence and rise, driving bubble-foam rich magma up over pit crater rim and onto the shield flanks. d) As magma rise rate lowers and gas is further exsolved, volume decreases in lava lake cause its lowering and retreat back into the pit crater. Drainage of lava below the northnorthwest part of the rim cause some parts of the chilled surface layer to flow back into the pit crater, exposing the bubble rich middle flow, and causing additional gas loss and surface evolution. e) In final stages of eruption, gas builds up below the lava lake floor thermal boundary layer, foams are extruded through flexing and cracking of the floor, followed by final solidification and floor subsidence. 
SUBSTRATE CHARACTERISTICS FOLLOWING FINAL COOLING AND SOLIDIFICIATION
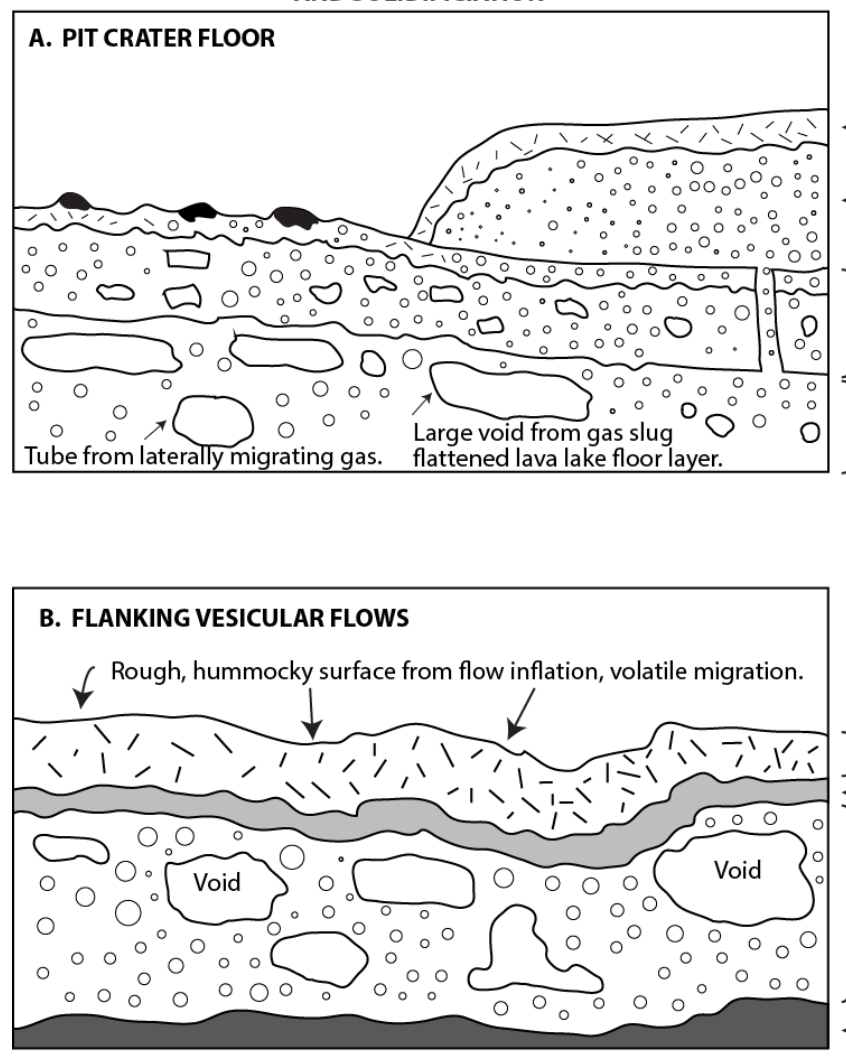

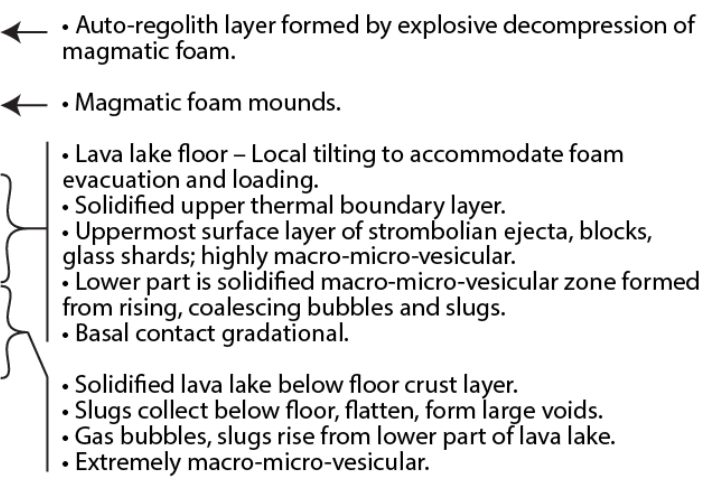

- Lava lake floor - Local tilting to accommodate foam evacuation and loading.

- Solidified upper thermal boundary layer.

- Uppermost surface layer of strombolian ejecta, blocks,

glass shards; highly macro-micro-vesicular.

- Lower part is solidified macro-micro-vesicular zone formed

from rising, coalescing bubbles and slugs.

- Basal contact gradational.

- Solidified lava lake below floor crust layer.

- Slugs collect below floor, flatten, form large voids.

- Gas bubbles, slugs rise from lower part of lava lake.

- Extremely macro-micro-vesicular.

Figure 14. Detailed cross-section of the interpreted final configuration of the substrate in (a) the Cauchy 5 pit crater interior and (b) the flanking bubble-rich/vesicular lava flows.

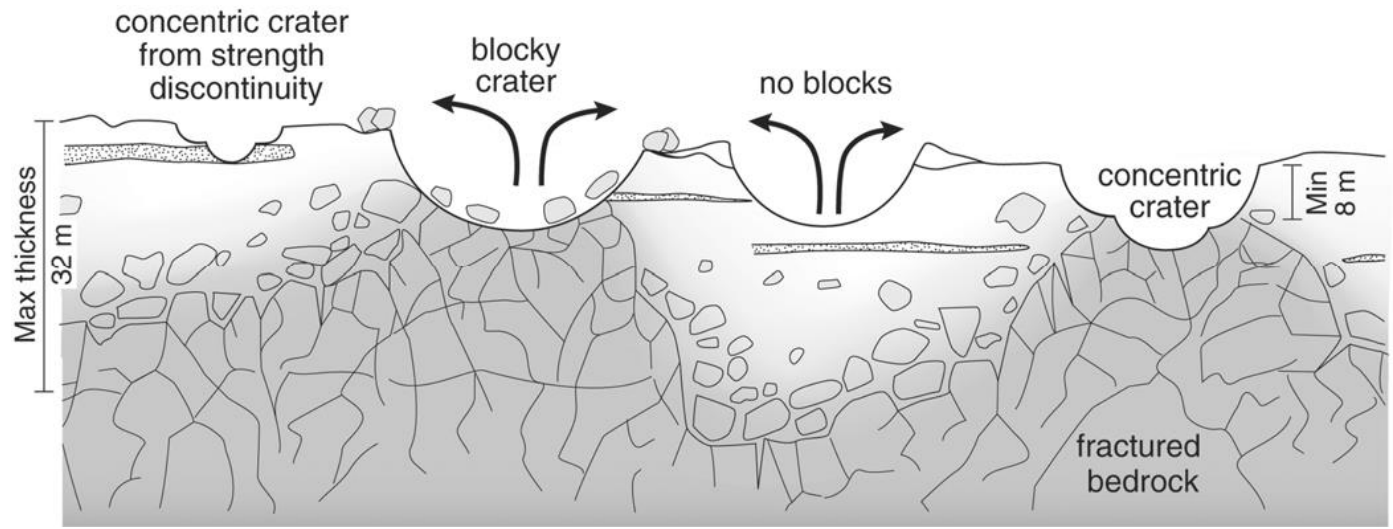

Figure 15. The typical model of lunar regolith development from uneven and fractured bedrock surface, and the characteristics of superposed impact craters (from Wilcox et al., 2005 with kind permission of John Wiley and Sons). Impact craters developed entirely in regolith will be nonblocky, impacts into the bedrock will produce blocky craters, and impacts into a strength discontinuity (typically regolith layer above bedrock) will result in concentric craters. 

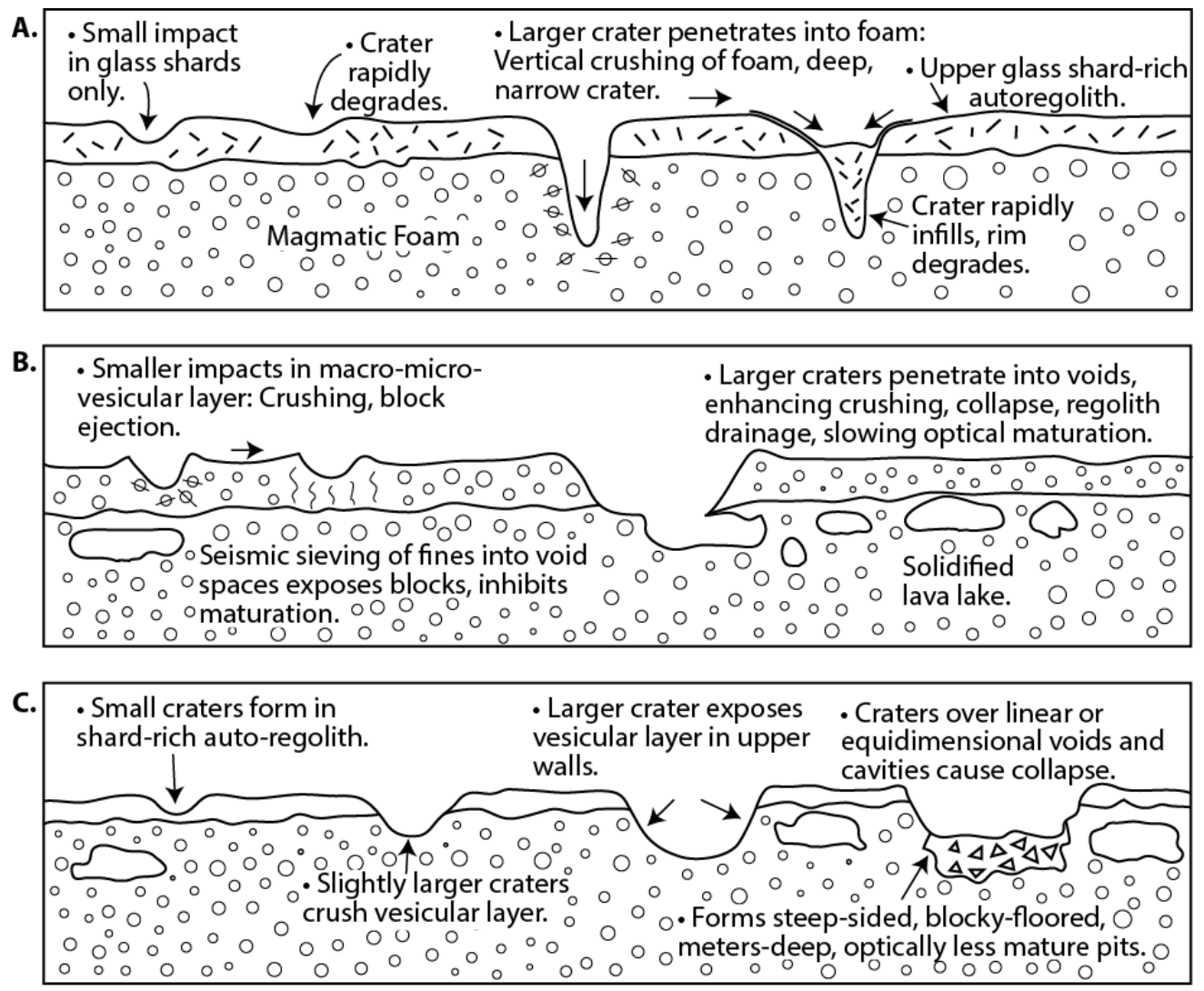

Figure 16. Nature of final substrates in the Cauchy 5 shield volcano and the implications for superposed impact craters of various sizes and their evolution and degradation. (a) Mounds in the Cauchy 5 pit crater interior and floor. (b) Rough floor areas of the pit crater interior. (c) Flanking flows of the small shield. Note the unusual effects of superposed craters (e.g., Head \& Ivanov, 2019; Ivanov \& Head, 2019) and their degradation compared to those in solid basalt substrates such as portrayed in Figure 15. 

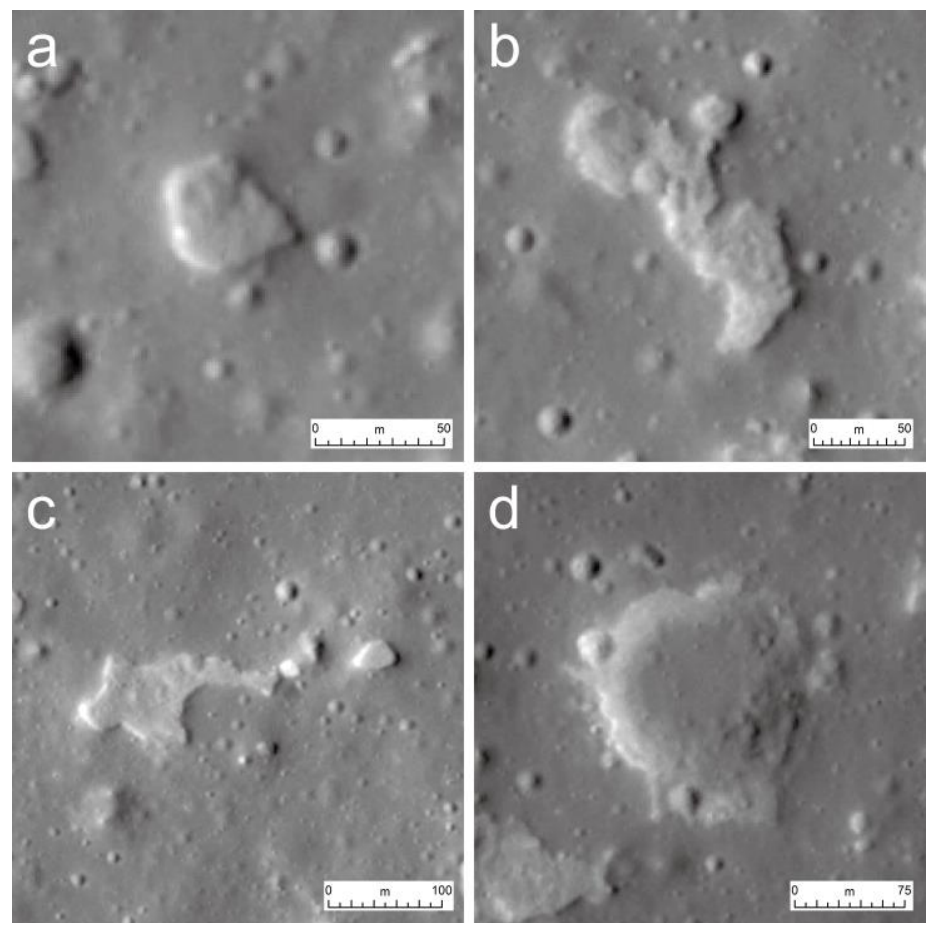

Figure 17. Examples of Type 2 IMPs on the Cauchy 5 small shield flanks and their interpreted origins: a) impact-induced mechanical collapse of surface into underlying layer void space, forming pits with a blocky immature deposit on the floor and exposing adjacent fresh layers in the pit walls); b) shock-induced shattering of bubble and foam walls and collapse of overlying layers producing depressions and pits that are highly irregular in shape; c) a variety of craters with non-traditional morphologies, degradation states and morphometries due to lateral and vertical variations in size and distribution of layer pore space and the effects on energy partitioning; d) an even larger impact event that penetrate through the entire flanking flow into the underlying solid basalt shield and regional mare substrate deposits, exposing the porous layer in the upper part of their walls. All sub-panels are from LROC NAC frame M1108025067. 